\title{
Snake venomics of monocled cobra (Naja kaouthia) and investigation of human IgG response against venom toxins
}

Laustsen, Andreas Hougaard; Gutiérrez, José María; Lohse, Brian; Rasmussen, Arne R.; Fernández, Julián; Milbo, Christina; Lomonte, Bruno

\section{Published in:}

Toxicon

Link to article, DOI:

10.1016/j.toxicon.2015.03.001

Publication date:

2015

Document Version

Peer reviewed version

Link back to DTU Orbit

Citation $(A P A)$ :

Laustsen, A. H., Gutiérrez, J. M., Lohse, B., Rasmussen, A. R., Fernández, J., Milbo, C., \& Lomonte, B. (2015). Snake venomics of monocled cobra (Naja kaouthia) and investigation of human IgG response against venom toxins. Toxicon, 99, 23-35. https://doi.org/10.1016/j.toxicon.2015.03.001

\section{General rights}

Copyright and moral rights for the publications made accessible in the public portal are retained by the authors and/or other copyright owners and it is a condition of accessing publications that users recognise and abide by the legal requirements associated with these rights.

- Users may download and print one copy of any publication from the public portal for the purpose of private study or research.

- You may not further distribute the material or use it for any profit-making activity or commercial gain

- You may freely distribute the URL identifying the publication in the public portal 

Julián Fernández ${ }^{2}$, Christina Milbo ${ }^{1,4}$, Bruno Lomonte ${ }^{2}$

${ }^{1}$ Department of Drug Design and Pharmacology, Faculty of Health and Medical Sciences, University of Copenhagen, Denmark

Running title: Proteomics of monocled cobra venom

16

Address for correspondence:

Dr Bruno Lomonte

Professor

Instituto Clodomiro Picado

Facultad de Microbiología

Universidad de Costa Rica

San José, COSTA RICA

bruno.lomonte@ucr.ac.cr 


\section{$29 \quad$ Highlights}

30

- The venom proteome of the monocled cobra, Naja kaouthia, is presented

- Most abundant venom components are three-finger toxins (neurotoxins and cytotoxins) and phospholipases $\mathrm{A}_{2}$

- Toxicity $\left(\mathrm{LD}_{50}\right)$ screening identified three-finger toxins as the most medically

35 relevant of this venom

- IgG response from a self-immunized human was significant against several toxins,

37 although weak against those with higher toxicity

38 


\section{Abstract}

The venom proteome of the monocled cobra, Naja kaouthia, from Thailand, was characterized by RP-HPLC, SDS-PAGE, and MALDI-TOF-TOF analyses, yielding 38 different proteins that were either identified or assigned to families. Estimation of relative protein abundances revealed that venom is dominated by three-finger toxins $(77.5 \%$; including $24.3 \%$ cytotoxins and $53.2 \%$ neurotoxins) and phospholipases $\mathrm{A}_{2}(13.5 \%)$. It also contains lower proportions of components belonging to nerve growth factor, ohanin/vespryn, cysteine-rich secretory protein, C-type lectin/lectin-like, nucleotidase, phosphodiesterase, metalloproteinase, L-amino acid oxidase, cobra venom factor, and cytidyltransferase protein families. Small amounts of three nucleosides were also evidenced: adenosine, guanosine, and inosine. The most relevant lethal components, categorized by means of a 'toxicity score', were $\alpha$-neurotoxins, followed by cytotoxins/cardiotoxins. IgGs isolated from a person who had repeatedly self-immunized with a variety of snake venoms were immunoprofiled by ELISA against all venom fractions. Stronger responses against larger toxins, but lower against the most critical $\alpha$ neurotoxins were obtained. As expected, no neutralization potential against N. kaouthia venom was therefore detected. Combined, our results display a high level of venom complexity, unveil the most relevant toxins to be neutralized, and provide prospects of discovering human IgGs with toxin neutralizing abilities through use of phage display screening. (199 words) 
 \\ 1. Introduction}

Snakebite is a serious medical condition affecting a large number of people worldwide; especially in impoverished rural areas of Asia, Africa and Latin America (Gutiérrez et al., 2006; Warrell, 2010a). Asia is the continent where the majority of these bites take place, and also where most deaths occur (Alirol et al., 2010; Chippaux, 1998; Kasturiratne et al., 2008). Currently there are 29 recognized extant species of terrestrial cobras assigned to the genus Naja (Utez and Hošek, 2015). Of these, 11 species are found in Asia, and 18 inhabit Africa (Utez and Hošek, 2015; Wallach et al., 2009). Among the cobras, Naja kaouthia (monocled cobra) is widespread in southern Asia and responsible for a significant part of the bites recorded (Viravan et al., 1986; Warrell, 1995; Kulkaew et al., 2009). A study in Bangladesh discovered records of 764 snakebites during 1988-1989, of which $34 \%$ of the 168 deaths ( $22 \%$ case fatality) were attributed to the cobras Naja naja and N. kaouthia (Warrell, 2010b). N. kaouthia occurs from north-eastern India, Bangladesh and Bhutan, across southern China, southward to northern Peninsular Malaysia (Prakash et al., 2012; Wüster, 1996) and is common in most of its range (Stuart and Wogan, 2012). N. kaouthia is adapted to a broad range of habitats, including agricultural land, human settlements, and bigger cities. However, its natural habitat includes paddy fields, swamps, mangroves, grasslands, scrublands and forest (Stuart and Wogan, 2012). The diet of $N$. kaouthia covers a broad range of animals from frogs, snakes, small birds to mammals (Cox et al., 1998), and even fish (Kyi and Zug, 2003). N. kaouthia is assessed as Least Concern at IUCN Red List of Threatened Species because of its large distribution, tolerance of a broad range of modified habitats, and is reported to be in abundance (Stuart and Wogan, 2012). In Thailand it has been reported that many cases of hospitalization due to snakebite 
were caused by $N$. kaouthia (Kulkeaw et al., 2009). Human envenomings by $N$. kaothia are predominantly characterized by neuromuscular paralysis which in severe cases ends up in respiratory paralysis, and by local tissue damage, i.e. swelling, necrosis and blistering (Warrell, 1995; Wongtongkam et al., 2005).

Enzymatic activities and toxicity of the venom of $N$. kaouthia have previously been studied (Pakmanee et al., 1998; Mukherjee and Maity, 2001; Das et al., 2013). Furthermore, a qualitative proteome of the venom has been reported showing the presence of 61 proteins belonging to 12 protein families (Kulkaew et al., 2007). The most prominent component is the long $\alpha$-neurotoxin $\alpha$-cobratoxin (Richard et al., 2013), constituting about $25 \%$ of the venom (Kulkaew et al., 2009) and belonging to the three-finger toxin family, of which $N$. kaouthia venom has several other members (Kulkaew et al., 2007). Other proteins that have been studied include phospholipases $\mathrm{A}_{2}\left(\mathrm{PLA}_{2} \mathrm{~S}\right)$ (Joubert and Taljaard, 1980a; Reali et al., 2003; Doley and Mukherjee, 2003), L-amino acid oxidases (Tan and Swaminathan, 1992; Sakurai et al., 2001), cardiotoxins (Joubert and Taljaard, 1980b; Fletcher et al., 1991; Debnath et al., 2010; Jamunaa et al., 2012), and nerve growth factors (Kukhtina et al., 2001). However, a proteomic analysis of this venom that integrates an estimation of relative protein abundances together with a detailed screening of the toxicity of its various components, is pending. An integrated functional and proteomic characterization of $N$. kaouthia venom is relevant not only for a deeper understanding of the composition of the venom and its relationships to toxicity, but also to establish a basic platform for antivenomic analyses.

Developing more potent antivenoms with better safety profiles is of medical relevance. Besides the traditional animal-derived antivenoms generated by immunization of horses with pools of snake venoms (Gutiérrez et al., 2011), various alternative approaches 
108 have been pursued at the experimental level in order to generate more specific antibody109 based therapies aimed at neutralizing the most important toxins in the venom. One 110 approach has been to raise murine antibodies specific towards relevant $N$. kaouthia toxins 111 (Charpentier et al., 1990; Masathien et al., 1994). Another approach for identifying potent 112 antitoxins is phage display screening (Roncolato et al., 2015). By using this methodology, 113 inhibitors against $N$. kaouthia toxins have been identified for both $\mathrm{PLA}_{2} \mathrm{~S}$ (Chavanayarn et 114 al., 2012) and $\alpha$-cobratoxin (Stewart et al., 2007; Kulkaew et al., 2009; Richard et al., 115 2013). These studies discovered inhibitors through screening of phage display libraries based on heavy chain fragments obtained from llama. Although promising, it could, however, be argued that llama-derived inhibitors, despite being much smaller than whole IgG antibodies and therefore likely to be less immunogenic, are still non-human. An 119 alternative to overcome this problem is based on modern antibody humanization procedures 120 (Safdari et al., 2013). In another study, inhibitors based on human single chain Fv (scFv) 121 fragments from non-immunized donors were developed (Kulkaew et al., 2009). These scFv fragments were not effective in rescuing mice injected with venom, which is likely to be due to naïve origin of the gene library for these fragments, since none of the human donors had been exposed to snake venom. Thus, the search for novel approaches to generate human antibodies against cobra venom toxins remains a challenge.

With this study, we report for the first time a venomics-based quantitative estimation of the proteome and a full protein lethality profile for $N$. kaouthia venom, in order to lay the foundation for developing a recombinant antivenom by identifying the most relevant toxins present in this venom. Furthermore, we uncover the presence of human $\operatorname{IgG}$

130 antibodies specific to $N$. kaouthia venom in the serum obtained from a unique individual exposed to low doses of a wide variety of snake venoms over a period of more than 25 
132 years. The binding ability of his antibodies, as well as of those from a person bitten twice

133 by the Southern Burrowing Asp, Atractaspis bibronii, was tested against the different

134 venom fractions from N. kaouthia, in comparison to a healthy volunteer unexposed to snake venoms. Finally, the neutralizing ability against $N$. kaouthia venom of the purified human IgG antibodies was evaluated in a mouse model.

\section{Materials and Methods}

\subsection{Snake venom}

Naja kaouthia venom was obtained from Latoxan SAS, Valence, France. The venom is a pool collected from several specimens, originally from Thailand.

\subsection{Venom separation by reverse-phase HPLC and SDS-PAGE}

Following the 'snake venomics' analytical strategy (Calvete, 2011), crude venom was fractionated by a combination of RP-HPLC and SDS-PAGE separation steps. Venom (2 mg) was dissolved in $200 \mu \mathrm{L}$ of water containing $0.1 \%$ trifluoroacetic acid (TFA; solution A) and separated by RP-HPLC (Agilent 1200) on a $\mathrm{C}_{18}$ column $(250 \times 4.6 \mathrm{~mm}, 5$ $\mu \mathrm{m}$ particle; Teknokroma). Elution was carried out at $1 \mathrm{~mL} / \mathrm{min}$ by applying a gradient towards solution B (acetonitrile, containing $0.1 \%$ TFA): $0 \%$ B for 5 min, $0-15 \%$ B over 10 min, $15-45 \%$ B over $60 \mathrm{~min}, 45-70 \%$ B over $10 \mathrm{~min}$, and 70\% B over 9 min, as previously described (Lomonte et al., 2014a). Manually collected fractions were dried in a vacuum centrifuge, redissolved in water, reduced with $5 \% \beta$-mercaptoethanol at $100{ }^{\circ} \mathrm{C}$ for $5 \mathrm{~min}$, and further separated by SDS-PAGE in $12 \%$ gels (Bio-Rad). Proteins were stained with colloidal Coomassie blue G-250, and gel images were acquired on a ChemiDoc ${ }^{\circledR}$ recorder using ImageLab ${ }^{\circledR}$ software (Bio-Rad). 


\subsection{Protein identification by tandem mass spectrometry of tryptic peptides}

Protein bands were excised from the polyacrylamide gels and subjected to reduction (10 $\mathrm{mM}$ dithiothreitol), alkylation (50 $\mathrm{mM}$ iodoacetamide), and overnight in-gel digestion with sequencing grade trypsin (Sigma), in $50 \mathrm{mM}$ ammonium bicarbonate at $37^{\circ} \mathrm{C}$. The resulting tryptic peptides were extracted with $50 \%$ acetonitrile containing $1 \%$ TFA, and analyzed by MALDI-TOF-TOF on an AB4800-Plus Proteomics Analyzer (Applied Biosystems). Peptides were mixed with an equal volume of saturated $\alpha$-cyanohydroxycinnamic acid (in 50\% acetonitrile, $0.1 \%$ TFA), and spotted $(1 \mu \mathrm{L})$ onto an OptiTOF 384-well plate, dried, and analyzed in positive reflector mode. TOF spectra were acquired using 1500 shots and a laser intensity of 3000 . The ten most intense precursor ions were automatically selected and their TOF/TOF fragmentation spectra were acquired using 500 shots at a laser intensity of 3900. External calibration in each run was performed with CalMix $^{\circledR}$ standards (ABSciex) spotted onto the same plate. For protein identification, resulting spectra were searched against the UniProt/SwissProt database using ProteinPilot ${ }^{\circledR}$ v.4 and the Paragon ${ }^{\circledR}$ algorithm (ABSciex) at $\geq 95 \%$ confidence, or manually interpreted. Few peptide sequences with lower confidence scores were manually searched using BLAST (http://blast.ncbi.nlm.nih.gov) for protein similarity and protein family assignment. RP-HPLC fractions corresponding to small molecules, eluting in the initial peaks of the chromatogram, were analyzed by ESI-MS/MS on a Q-Trap ${ }^{\circledR} 3200$ instrument (Applied Biosystems). Samples $(10 \mu \mathrm{L})$ were loaded into metal-coated capillary tips (Proxeon) and directly infused into a nano-ESI source (Protana) operated at 1300 V. Spectra were acquired in positive Enhanced Resolution mode. nESI-MS performed in this instrument was also used to determine the isotope-averaged mass of intact proteins in selected peaks 
180 from the RP-HPLC separation. For this purpose, mass spectra were acquired in Enhanced

181 Multicharge mode in the $\mathrm{m} / \mathrm{z}$ range $700-1700$, and deconvoluted with the aid of the

182 Analyst $^{\circledR}$ v.1.5 software (ABSciex).

183

\subsection{Relative protein abundance estimations}

The relative abundances of the venom proteins identified were estimated by integrating the areas of their chromatographic peaks at $215 \mathrm{~nm}$, using the ChemStation ${ }^{\circledR}$ software (Agilent), which correlates with peptide bond abundance (Calvete, 2011). For HPLC peaks containing several electrophoretic bands, their percentage distributions were assigned by densitometry, using ImageLab ${ }^{\circledR}$ (Bio-Rad).

\subsection{Nucleoside and FAD analysis}

The presence of selected nucleosides (adenosine, inosine, guanosine), and flavine adenine dinucleotide (FAD) was determined by spiking a sample of $1 \mathrm{mg}$ of venom with 10 $\mu \mathrm{g}$ of each nucleoside or FAD, respectively, and separating it by reverse-phase HPLC as described in section 2.2. If the nucleoside or FAD peak coincided with a peak already present in a crude venom sample (as judged by the increment in the height of the peak), and if this venom peak showed an ESI-MS spectrum similar to that of the nucleoside or FAD, the identity of venom component was judged to be the same as the nucleoside or FAD. Further confirmation of the molecular identities of the nucleosides was obtained by acquiring their collision-induced dissociation MS/MS spectra in positive mode, using the Enhanced Product Ion tool of the Analyst v1.5 in the QTrap 3200 mass spectrometer as described (Laustsen et al., 2015). The abundance for nucleosides given in Table 1 is only indicative of an approximate value, due to differences in absorbance at $215 \mathrm{~nm}$ between 
nucleosides and proteins.

\subsection{In vitro enzymatic activities}

\subsubsection{Phospholipase $A_{2}$ activity}

$\mathrm{PLA}_{2}$ activity was assayed on the monodisperse synthetic chromogenic substrate 4nitro-3-octanoyloxybenzoic acid (NOBA) (Holzer and Mackessy, 1996). Twenty-five $\mu \mathrm{L}$ containing various amounts of venom were mixed with $200 \mu \mathrm{L}$ of $10 \mathrm{mM}$ Tris, $10 \mathrm{mM}$ $\mathrm{CaCl}_{2}, 0.1 \mathrm{M} \mathrm{NaCl}, \mathrm{pH} 8.0$, and $25 \mu \mathrm{L}$ of NOBA to achieve a final substrate concentration of $0.32 \mathrm{mM}$. Plates were incubated at $37{ }^{\circ} \mathrm{C}$ for $60 \mathrm{~min}$, and absorbances were recorded at $405 \mathrm{~nm}$ in a microplate reader. Samples were assayed in triplicates.

\subsubsection{Proteinase activity}

Variable amounts of venom (10 to $40 \mu \mathrm{g}$ ) were added to $100 \mu \mathrm{L}$ of azocasein (10

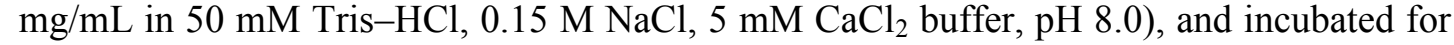
$90 \mathrm{~min}$ at $37^{\circ} \mathrm{C}$. The reaction was stopped by addition of $200 \mu \mathrm{L}$ of $5 \%$ trichloroacetic acid, and after centrifugation ( $5 \mathrm{~min}, 13,000 \mathrm{rpm}$ ), $150 \mu \mathrm{L}$ of supernatants were mixed with $100 \mu \mathrm{L}$ of $0.5 \mathrm{M} \mathrm{NaOH}$, and absorbances were recorded at $450 \mathrm{~nm}$. The absorbance of azocasein incubated with distilled water alone was used as a blank, being subtracted from all readings (Wang et al. 2004). Samples were assayed in triplicates.

\subsection{Toxicological profiling}

\subsubsection{Animals}

In vivo assays were conducted in $\mathrm{CD}-1$ mice, supplied by Instituto Clodomiro Picado, following protocols approved by the Institutional Committee for the Use and Care 
of Animals (CICUA), University of Costa Rica. Mice were housed in cages for groups of 4-8, and were provided food and water ad libitum.

\subsubsection{Toxicity of crude venom and isolated toxins}

The lethality of the whole venom and fractions or isolated toxins was tested by intravenous (i.v.) injection in groups of four mice (18-20 g body weight). Various amounts of venom or fractions/toxins were dissolved in phosphate-buffered saline (PBS; $0.12 \mathrm{M}$ $\mathrm{NaCl}, 0.04 \mathrm{M}$ sodium phosphate buffer, $\mathrm{pH}$ 7.2), and injected in the caudal vein, using an injection volume of $100 \mu \mathrm{L}$. Then, deaths occurring within $24 \mathrm{hr}$ were recorded. Median lethal dose $\left(\mathrm{LD}_{50}\right)$ was calculated by probits (Finney, 1971), using the BioStat ${ }^{\circledR}$ software (AnalySoft).

The toxicity of venom fractions was initially screened by selecting a dose based on fraction abundance. The dose was selected to assess whether the fraction would score above or below 5 according to the Toxicity Score defined by Laustsen et al. (2015), which represents the ratio of protein fraction abundance (\%) in the venom divided by its estimated $\mathrm{LD}_{50}$ in CD-1 mice by i.v. injection. Fractions that were not lethal at this dose (yielding a Toxicity Score $<5$ ) were considered as having insignificant toxicity. All fractions that were lethal at this level, and some fractions killing mice at a Toxicity Score level between 1-5 were further evaluated, and precise $\mathrm{LD}_{50}$ values were further determined for them. Groups of 3-5 mice per dose were used in order to minimize the use of experimental animals.

\subsection{Preparation of human IgGs and human serum}

\subsubsection{Donor 1}


This donor has over a period of 25 year injected himself with sub-lethal amounts of venom from the following snakes: Viridovipera (formerly Trimeresurus) stejnegeri, Trimeresurus nebularis, T. macrops, T. popeorum, T. trigonocephalus, T. albolabris, T. venustus, Bothriechis schlegelii, Crotalus enyo enyo, Naja kaouthia, N. naja, N. siamensis, Agkistrodon contortrix, A. bilineatus, Bothrops asper, Crotalus oreganus, Crotalus oreganus helleri, Cerastes cerastes, and Micrurus fulvius. In the last 5 years, this individual has been injecting himself with venom from Naja kaouthia on an average of every 2 weeks. Brian Lohse has a written consent from the Danish scientific ethical council (H-3-2013FSP60) to use the blood sample from this donor according to the law of the ethical committee $\S 2.1$. After having provided written and oral information about the project to this donor, written consent was given for obtaining blood samples and for performing the experiments included in the present work. The donor requested the inclusion of his name to be acknowledged in publications.

\subsubsection{Donor 2}

Donor 2 is an entomologist, who was unfortunate to be bitten twice by the snake Atractaspis bibronii (Southern Burrowing Asp) during fieldwork in August 2013. After having provided written and oral information about the project to this donor, written consent was given for obtaining blood samples and for performing the experiments here included. The donor requested the inclusion of his name to be acknowledged in publications.

\subsubsection{Blood sampling for obtaining IgGs}


$200 \mathrm{ml}$ of blood was sampled from each donor in Vacuette ${ }^{\circledR}$ tubes of $4 \mathrm{~mL}$, containing Z Serum Clot Activator (Greiner bio-one). Every tube was gently tilted up and down ten times as soon as it was filled with blood to ensure thorough mixing with the coagulation factor. The tubes were kept at room temperature until full coagulation (30 min). Then, tubes were centrifuged at $3000 \mathrm{~g}$ for $10 \mathrm{~min}$, and the serum was transferred to cryotubes and stored at $-20^{\circ} \mathrm{C}$.

\subsubsection{Protein A purification of $\operatorname{Ig} G$ antibodies}

After filtration of serum through a $0.45 \mu \mathrm{m}$ membrane, the procedure accompanying the Protein A Antibody Purification Kit (PURE1A, Sigma-Aldrich) was followed in order to obtain human $\operatorname{IgG}$ antibodies in solution at physiological $\mathrm{pH}$. IgG antibodies were stored at $4{ }^{\circ} \mathrm{C}$.

\subsubsection{Preparation of human serum from healthy volunteer}

Blood was obtained from a healthy donor to serve as a negative control. After clotting, serum was separated by centrifugation, and stored at $-20^{\circ} \mathrm{C}$.

\subsection{Immunoreactivity of human IgGs against venom fractions by ELISA}

Wells in MaxiSorp plates (NUNC, Roskilde, Denmark) were coated overnight with $0.6 \mu \mathrm{g}$ of each HPLC venom fraction dissolved in $100 \mu \mathrm{L}$ PBS. Then, wells were blocked by adding $100 \mu \mathrm{L}$ PBS containing 2\% (w:v) bovine serum albumin (BSA, Sigma) and leaving the plates on a mixer at room temperature for $1 \mathrm{~h}$. Plates were then washed five times with PBS. A dilution of each human IgG pool in PBS $+2 \%$ BSA was prepared such that the concentration of $\mathrm{IgG}$ proteins was $86 \mu \mathrm{g} / \mathrm{mL}$ (as measured by their absorbance at 
$280 \mathrm{~nm}$ on a NanoDrop ${ }^{\circledR} 2000 \mathrm{c}$ instrument, Thermo Scientific). Then, $100 \mu \mathrm{L}$ of these $\mathrm{IgG}$ solutions were added to the wells, after which the plates were incubated for $2 \mathrm{~h}$, followed by five additional washings with PBS. Then, $100 \mu \mathrm{L}$ of a 1:2000 dilution of affinitypurified goat anti-human IgG (gamma-chain specific) antibodies conjugated to alkaline phosphatase (Cappel, Organon Teknika) in PBS $+2 \%$ BSA was added to each well. The plates were incubated for $2 \mathrm{~h}$, and then washed five times with FALC buffer $(0.05 \mathrm{M}$ Tris, $0.15 \mathrm{M} \mathrm{NaCl}, 20 \mu \mathrm{M} \mathrm{ZnCl}_{2}, 1 \mathrm{mM} \mathrm{MgCl}_{2}, \mathrm{pH}$ 7.4). Color development was achieved by the addition of $100 \mu \mathrm{L} p$-nitrophenyl phosphate $(1 \mathrm{mg} / \mathrm{mL}$ in $9.7 \% \mathrm{v} / \mathrm{v}$ diethanolamine buffer, $\mathrm{pH}$ 9.8). The absorbances at $405 \mathrm{~nm}$ were recorded (Multiskan FC, Thermo Scientific) at several time intervals.

\subsection{Neutralization studies with human IgGs}

After purification according to section 2.8.4, the human IgGs were kept refrigerated. Six months later, $3 \mathrm{~mL}$ of $\mathrm{IgGs}$ were dialyzed against $2 \mathrm{~L}$ of PBS overnight and lyophilized. The IgGs were reconstituted in $500 \mu \mathrm{L}$ PBS and the protein concentration was measured on NanoDrop to be $14 \mathrm{mg} / \mathrm{ml}$. IgG was mixed with venom at a ratio of $78 \mathrm{mg}$ $\mathrm{IgG} / \mathrm{mg}$ venom and incubated at $37^{\circ} \mathrm{C}$ for $30 \mathrm{~min}$. Aliquots of $120 \mu \mathrm{L}$ of this mixture, containing $4 \mathrm{LD}_{50} \mathrm{~s}$ of venom, were then injected i.v. into a group of four mice (18-20 g) and deaths occurring within $24 \mathrm{hr}$ were recorded.

\subsection{Results and Discussion}

\subsection{Venomics}

A proteomic characterization of $N$. kaouthia venom coupled with an estimation of its protein relative abundances was, with this study, carried out for the first time. Twenty- 
322 eight peaks from the venom were resolved by RP-HPLC. The first three fractions eluting 323 from the column were non-peptidic, while the remaining 25 peaks were further resolved into 50 protein bands by SDS-PAGE separation (Fig.1). In-gel digestion and MALDI-TOFTOF analysis of these yielded a total of 38 identified proteins, while only 4 remained unknown. Altogether, the unidentified venom components represent less than $1 \%$ of the total venom protein content, while the rest were either identified or assigned to protein families (Table 1). A previous qualitative proteomic profile was reported for this venom, describing matches to 61 orthologous proteins classified into 12 groups (Kulkaew et al., 2007). Of these, oxoglutarate dehydrogenase complex was identified on the basis of a single peptide that matched such enzyme from a prokaryote (Burkholderia cenocepacia), while serum albumin likely corresponds to contaminating traces derived from slight trauma that may occur during venom collection (see for example Lomonte et al., 2014b). In addition, the previous study considered cardiotoxins and cytotoxins as two different protein groups, in spite of these two names being used to refer to the same type of toxins, structurally classified within the three-finger toxin family (Kini and Doley, 2010). Our results are concordant with the remaining eight protein families detected by Kulkaew et al. (2007), but further expand the proteomic profile of $N$. kaouthia venom with the addition of members belonging to the nerve growth factor, ohanin-like/vespryn, C-type lectin/lectinlike, nucleotidase, phosphodiesterase, L-amino acid oxidase, and cytidyltransferase protein families (Table 1 and Fig.2), and moreover, providing a quantitative estimation of their relative abundances in the venom.

Peaks 1 to 3 were analyzed by direct infusion using nESI-MS/MS, since they did not show proteins by gel electrophoresis. Peaks 2 and 3 had molecular masses of $268 \mathrm{Da}$ and $283 \mathrm{Da}$, respectively, and the nucleoside analysis by HPLC (Fig.3) revealed their 
identities as adenosine and guanosine, respectively. Also, a trace of inosine between peaks 2 and 3 was detected by the nucleoside analysis by HPLC (Fig.3).

All peptidic peaks were tested in vivo for acute toxicity, except for peaks 23 and 26, which yielded very low amounts of proteins (Table 2), and peaks 24, 27, and 28, which correspond to metalloproteinases, enzymes known to be inactivated by the RP-HPLC separation procedure. In Fig.2, the overall protein composition of the venom of N. kaouthia, expressed as percentage of total protein and nucleoside content, is represented. Two main families predominate in the venom: Three-finger toxins (3FTx; $77.5 \%$, of which $24.3 \%$ are cytotoxins, the rest being neurotoxins) and $\mathrm{PLA}_{2} \mathrm{~S}\left(\mathrm{PLA}_{2} ; 13.5 \%\right)$. In partial agreement with previous findings, the major single component of the three-finger toxins was determined to be alpha-elapitoxin-Nk2a ( $\alpha$-cobratoxin), a long-chain neurotoxin. However, in our results, this toxin represented $32.3 \%$ of the whole venom, which is significantly higher than the reported values of 23-25\% (Kulkaew et al., 2009). This increase might reflect either geographical variations in venom composition or differences in methodology. As other $\alpha-$ neurotoxins, alpha-elapitoxin-Nk2a is able to bind to nicotinic receptors at the motor endplate of muscle fibers, thus generating a flaccid paralysis leading to respiratory failure and death (Ultsintong et al., 2009; Alkondon et al., 1990). This type of neurotoxin is responsible for the life-threatening neuromuscular paralysis in human victims of neurotoxic cobra bites (Warrell, 1995).

An interesting finding, discovered by the lack of high acute toxicity in the rodent model (Table 2), and reinforced by the difference in human IgG binding in the ELISA assays (Fig.6) was that the protein identified in peak 10 as alpha-elapitoxin-Nk2a appears to correspond to a closely related homolog. In order to validate this, both peak 10 and peak 6 
(known to contain alpha-elapitoxin-Nk2a) were analyzed by nESI-MS/MS (Fig.5), according to which their masses were 7619 and $7826 \mathrm{Da}$, respectively (alpha-elapitoxinNk2a has a reported mass of 7831 Da according to: http://www.uniprot.org/uniprot/P01391). Thus, peak 10 should be a homolog of alphaelapitoxin-Nk2a sharing peptide sequences (Table 1), but different by $207 \mathrm{Da}$ in total mass. Since the toxicity of this protein is markedly lower in comparison to alpha-elapitoxin-Nk2a, further studies to determine its complete amino acid sequence and bioactivities could be of interest, as it represents nearly $10 \%$ of the venom proteome.

In addition to $\alpha$-neurotoxins, other representatives of the three-finger toxin family detected in N. kaouthia venom proteome are the so-called 'cytotoxins' (Table 1). These toxins are known to interact with and disrupt the integrity of plasma membrane of various cell types, thus inducing irreversible cell damage (Konshina et al., 2012). These cytotoxins are responsible for the local necrotic effect characteristic of envenomings by $N$. kaouthia (Warrell, 1995). Also, PLA 2 is commonly an abundant component in the majority of elapid venom proteomes characterized so far, and it was detected in our proteomic analysis in $N$. kaouthia venom. PLA 2 activity was confirmed for $N$. kaouthia venom in vitro, although it was significantly lower than for $M$. nigrocinctus, a Central American elapid species (Fig.4A). Elapid PLA $\mathrm{A}_{2}$ have been shown to exert a number of toxicological effects, such as myonecrosis (Bhat and Gowda, 1989; Harris, 1991), anticoagulation (Kini, 2005; Doley and Mukherjee, 2003), inhibition of platelet aggregation (Clemetson et al., 2007), and edema (Wang and Teng, 1990). In the case of N. kaouthia venom, PLA 2 s might contribute to the local inflammatory and necrotizing effects observed in human patients. Furthermore, cardiotoxins and $\mathrm{PLA}_{2} \mathrm{~s}$ act synergistically to induce cell membrane damage (Harvey et al., 1983), thus potentiating the tissue damaging effect of the venom. Altogether, a high 
proportion of the components of $N$. kaouthia venom belong to these two toxin families, i.e. three-finger toxins and $\mathrm{PLA}_{2} \mathrm{~s}$. This further supports the concept that high diversity within just a few toxin families may be a general theme within elapid venoms (Calvete, 2013; Laustsen et al., 2015). Such idea is supported also by findings of Vonk et al. (2013) on the genome of the elapid Ophiophagus hannah (king cobra), in which the three-finger toxins family was found to be highly diversified.

In amounts each representing $<2 \%$ of the total venom content, the venom also contains members of the nerve growth factor (NGF), Ohanin/vespryn (OHA), Cysteine-rich secretory protein (CRISP), C-type lectin/lectin-like (CTL), nucleotidase (NUCL), phosphodiesterase (PDE), metalloproteinase (MP), L-amino oxidase (LAO), Cobra venom factor (CVF), and Cytidyltransferase (CTT) families. The low content of proteinases is further supported by the negligible proteinase activity of the venom upon a general substrate such as azocasein (Fig.4B). Also, regarding non-peptidic material, small amounts were identified to be adenosine, inosine, and guanosine, which have also been detected in other snake venoms (Aird, 2002; Laustsen et al., 2015).

The results of toxicity testing of the fractions are summarized in Table 2 . Unsurprisingly, the lethality of the venom stems from the presence of potent $\alpha$-neurotoxins and cytotoxins, with $\mathrm{PLA}_{2}$ s playing a secondary role leading to local tissue damage at the bite wound. A Toxicity Score is shown in Table 2, which takes into account both potency and abundance. Toxins with a higher score, as estimated in mice, are expected to be of higher medical relevance. These are abundant and/or very potent, while toxins with a low score are less medically relevant. Based on this score, it is clear that alpha-elapitoxin-Nk2a is by far the toxin that is most clinically relevant to neutralize, with a value of 326 . Some toxins have very low $\mathrm{LD}_{50} \mathrm{~S}$ (particularly fractions 4 and 5), but due to their lower 
417 abundance their Toxicity Scores are much lower. Others have intermediate $\mathrm{LD}_{50}$ potencies, 418 but become relevant due to their high abundance (e.g. fraction 16). The cytotoxins present 419 in the venom act by a different mechanism than the $\alpha$-neurotoxins, providing $N$. kaouthia 420 venom with a dual strategy for prey subduction. It is interesting to note that the accumulated Toxicity Scores for all toxins amount to the same value as the Toxicity Score for the whole venom. This is not the case for the venom from the related elapid, Dendroaspis polylepis, which shows evidence of synergism, and where the accumulated Toxicity Scores is considerably lower than the Toxicity Score of whole venom (indicating synergism between the toxins and not simply additive effect) (Laustsen et al., 2015). One interpretation of this finding could be that $N$. kaouthia venom does not exert significant synergism, but instead relies on two complementary strategies for acute toxicity.

In terms of therapeutic targets, based on their Toxicity Score, the most relevant toxins in N. kaouthia venom that should be neutralized by an effective antivenom are (in order of importance): alpha-elapitoxin-Nk2a (P01391), cobrotoxin-c (P59276) and cobrotoxin-b (P59275), and the homolog of three-finger toxin from Naja atra (E2IU03), while the cytotoxins are of less importance in terms of overall lethality, although they are likely to play a relevant role in local necrosis, and hence should be neutralized by antivenoms. In addition, neutralization of $\mathrm{PLA}_{2} \mathrm{~S}$ should also be considered a priority in order to limit local tissue damage from envenomings. Thus, antivenomic studies with $N$. kaouthia venom should establish whether antivenoms are able to bind these toxins.

\subsection{Immunoreactivity of human IgGs against venom fractions}

The isolated human IgGs from the unique individual who had self-injected small amounts of venom from various different snakes, including $N$. kaouthia, showed significant 
binding ability to isolated venom fractions, clearly above the background established by serum of a healthy donor, or by IgGs from the donor bitten twice by a different snake species (Fig.6). It is evident that the antibody response of the individual exposed to $N$. kaouthia venom was higher against larger toxins present in later eluting peaks, while the response was limited against the most important $\alpha$-neurotoxins (peaks 4, 5, and 6), which could be due to the low immunogenicity of small toxins (Fernández et al., 2011). Therefore, it was not surprising that IgGs were unable to neutralize the lethality of whole venom when mice were challenged with $4 \mathrm{LD}_{50}$ s mixed with IgGs at a level of $0.013 \mathrm{mg}$ toxin per mg of IgGs. Nevertheless, it could be particularly interesting to further investigate these antibodies via phage display screening. In llamas, it has been shown that using naïve libraries for phage display screening did not yield high affinity inhibitors to snake toxins, while excellent inhibitors of alpha-elapitoxin-Nk2a were discovered this way, when a library from an immunized llama was used (Richard et al., 2013). Kulkeaw et al. (2009) were the first to report drug discovery effort using a human phage display library. However, they similarly did not find strong inhibitors of snake toxins, most likely given the fact that their library was naïve. Therefore, using the antibody genes from the unique donor to construct a phage display library, and subsequently screening this library, has the potential to yield toxin inhibitors of therapeutic value. Further studies of the donor's immune response against toxins from other snake species are warranted and may help direct phage display screening efforts towards the generation of new antibodies of human origin.

\subsection{Concluding remarks and outlook}

Differing from previous proteomic studies on $N$. kaouthia venom, the present work combined the cataloguing of venom proteins with an estimation of their relative 
abundances, together with an assessment of their lethal toxicity for mice. This approach uncovered that the most abundant group of proteins was three-finger toxins, followed by $\mathrm{PLA}_{2} \mathrm{~S}$. Based on an evaluation of the accumulation of Toxicity Scores and knowledge about toxin functions, the venom seems to have a dual strategy for prey subduction elicited by $\alpha$-neurotoxins and cytotoxins, between which pharmacological interaction is speculated only to be of additive value rather than synergism.

ELISA immunoprofiling of human IgGs isolated from a human donor, who had repeatedly injected himself with snake venom from various different species, revealed presence of antibodies with high binding ability to several of the isolated venom fractions, although not against the medically most relevant toxins of $N$. kaouthia. Still, the presence of these antibodies opens the prospect of discovering inhibitors of therapeutic value.

\section{Acknowledgments}

The authors thank Steve Ludwin and Thomas Pape for donation of blood samples for this study. We thank Dr. Steven D. Aird (Okinawa Institute of Science and Technology, Japan) for fruitful discussions about nucleosides present in snake venom. We further thank Jens Kringelum (Technical University of Denmark), Mikael Engmark (Technical University of Denmark), and Alexandra Bak Jakobsen (Denmark) for fruitful scientific discussions. We thank the Department of Drug Design and Pharmacology, University of Copenhagen, and Instituto Clodomiro Picado, Universidad de Costa Rica, for supporting the research. Finally, we are grateful to the following foundations for financial support: Drug Research Academy (University of Copenhagen), Dansk Tennis Fond Oticon Fonden, Knud Højgaards Fond, Rudolph Als Fondet, Henry Shaws Legat, Læge Johannes Nicolai Krigsgaard of Hustru Else Krogsgaards Mindelegat for Medicinsk Forskning og 
489 Medicinske Studenter ved Københavns Universitet, Lundbeckfonden, Torben of Alice 490 Frimodts Fond, Frants Allings Legat, Christian og Ottilia Brorsons Rejselegat for Yngre 491 Videnskabsmænd og -kvinder, and Fonden for Lægevidenskabens Fremme.

492

\section{Conflicts of interest statement}

494

The authors declare that there are no conflicts of interest related to this study. Sources that provided financial support were not involved in the collection, analysis, or interpretation of data, nor in writing the report and submitting it for publication.

497 


\section{References}

Aird, S.D., 2002. Ophidian envenomation strategies and the role of purines. Toxicon 40, $335-393$.

Alirol, E., Sharma, S.K., Bawaskar, H.S., Kuch, U., Chappuis, F., 2010. Snake bite in South Asia: a review. PLoS Negl. Trop. Dis. 4, e603.

Alkondon, M., Albuquerque, E.X., 1990. Alpha cobratoxin blocks the nicotinic acetylcholine receptor in rat hippocampal neurons. Eur. J. Pharmacol. 191, 505506.

Bhat, M.K., Gowda, T.V., 1989. Purification and characterization of a myotoxic phospholipase $\mathrm{A}_{2}$ from Indian cobra (Naja naja naja) venom. Toxicon 27, 861-873.

Calvete, J.J., 2011. Proteomic tools against the neglected pathology of snake bite envenoming. Expert Rev. Proteomics 8, 739-758.

Calvete, J.J., 2013. Snake venomics: from inventory of toxins to biology. Toxicon 75, 44 72.

Charpentier, I., Pillet, L., Karlsson, E., Couderc, J., Ménez, A., 1990. Recognition of the acetylcholine receptor binding site of a long-chain neurotoxin by toxin-specific monoclonal antibodies. J. Mol. Recognition 3, 74-81.

Chavanayarn, C., Thanongsaksrikul, J., Thueng-In, K., Bangphoomi, K., Sookrung, N., Chaicumpa, W., 2012. Humanized single-domain antibodies (VH/VHH) that bound specifically to Naja kaouthia phospholipase $\mathrm{A}_{2}$ and neutralized the enzymatic activity. Toxins $4,554-567$.

Chippaux, J.P., 1998. Snake-bites: appraisal of the global situation. Bull. World Health Organ. 76, 515-524. 
Chuman, Y., Nobuhisa, I., Ogawa, T., Deshimaru, M., Chijiwa, T., Tan, N.H., Fukumaki, Y., Shimohigashi, Y., Ducancel, F., Boulain, J.C, Ménez, A., Ohno, M., 2000. Regional and accelerated molecular evolution in group I snake venom gland phospholipase $\mathrm{A}_{2}$ isozymes. Toxicon $38,449-462$.

Clemetson, K.J., Lu, Q., Clemetson, J.M., 2007. Snake venom proteins affecting platelets and their applications to anti-thrombotic research. Curr. Pharm. Des. 13, 28872892.

Cox, M., Van Dijk, P.P., Nabhitabhata, J., Thirahupt, K., 1998. A photographic guide to snakes and other reptiles of Peninsular Malaysia, Singapore and Thailand. Ralph Curtis Books, Sanibel Island, Florida, 144 pp.

Das, D., Urs, N., Hiremath, V., Vishwanath, B.S., Doley, R., 2013. Biochemical and biological characterization of Naja kaouthia venom from North-East India and its neutralization by polyvalent antivenom. J. Venom Res. 4, 31-38.

Debnath, A., Saha, A., Gomes, A., Biswas, S., Chakrabarti, P., Giri, B., Biswas, A.K., Das Gupta, S., Gomes, A., 2010. A lethal cardiotoxic-cytotoxic protein from the Indian monocellate cobra (Naja kaouthia) venom. Toxicon 56, 569-579.

Doley, R., Mukherjee, A.K., 2003. Purification and characterization of an anticoagulant phospholipase $\mathrm{A}_{2}$ from Indian monocled cobra (Naja kaouthia) venom. Toxicon 41, $81-91$.

Fernández, J., Alape-Girón, A., Angulo, Y., Sanz, L., Gutiérrez, J.M., Calvete, J.J., Lomonte, B., 2011. Venomic and antivenomic analyses of the Central American coral snake, Micrurus nigrocinctus (Elapidae). J. Proteome Res. 10, 1816-1827.

Finney, D.J., 1971. Statistical Methods in Biological Assay. London: Charles Griffin and Company Ltd. 
Fletcher, J.E., Jiang, M.S., Gong, Q.H., Yudkowsky, M.L., Wieland, S.J., 1991. Effects of a cardiotoxin from Naja naja kaouthia venom on skeletal-muscle - Involvement of calcium-induced calcium release, sodium-ion currents and phospholipase $\mathrm{A}_{2}$ and phospholipase C. Toxicon 29, 1489-1500.

Gutiérrez, J.M., Theakston, R.D.G., Warrell, D.A., 2006. Confronting the neglected problem of snake bite envenoming: The need for a global partnership. PLoS Med 3, e150.

Gutiérrez, J.M., León, G., Lomonte, B., Angulo, Y., 2011. Antivenoms for snakebite envenomings. Inflamm. Allergy Drug Targets 10, 369-380.

Harris, J.B., 1991. Phospholipases in snake venoms and their effects on nerve and muscle. In: Snake Toxins (Harvey, A.L., Ed.), pp.91-129. New York, Pergamon Press.

Harvey, A.L., Hider, R.C., Khader, F., 1983. Effect of phospholipase A on actions of cobra venom cardiotoxins on erythrocytes and skeletal muscle. Biochim. Biophys. Acta $728,215-221$.

Holzer, M., Mackessy, S.P., 1996. An aqueous endpoint assay of snake venom phospholipase $\mathrm{A}_{2}$. Toxicon 34, 1149-1155.

Jamunaa, A., Vejayan, J., Halijah, I., Sharifah, S.H., Ambu, S., 2012. Cytotoxicity of Southeast Asian snake venoms. J. Ven. Animals Toxins incl. Trop. Dis. 18, 150156.

Joubert, F.J., Taljaard, N., 1980a. Purification, some properties and amino-acid sequences of two phospholipases A (CM-II and CM-III) from Naja naja kaouthia venom. Eur. J. Biochem. 112, 493-499. 
Joubert, F.J., Taljaard, N., 1980b. The complete primary structures of three cytotoxins (CM-6, CM-7 and CM-7A) from Naja naja kaouthia (Siamese cobra) snake venom. Toxicon 18, 455-467.

Karlsson, E., 1973. Chemistry of some potent animal toxins. Experientia 29, 1319-1327.

Kasturiratne, A., Wickremasinghe, R., de Silva, N., Gunawardena, N.K., Pathmeswaran, A., Premaratna, R., Savioli, L., Lalloo, D.G., de Silva, H.J., 2008. The global burden of snakebite: a literature analysis and modelling based on regional estimates of envenoming and deaths. PLoS Med. 5, e218.

Kini, R.M., Doley, R., 2010. Structure, function and evolution of three-finger toxins: mini proteins with multiple targets. Toxicon $56,855-867$.

Kini, R.M., 2005. Structure-function relationships and mechanism of anticoagulant phospholipase $A_{2}$ enzymes from snake venoms. Toxicon 45, 1147-1161.

Konshina, A.G., Dubovskii, P.V., Efremov, R.G., 2012. Structure and dynamics of cardiotoxins. Curr. Protein Pept. Sci. 13, 570-584.

Kukhtina, V.V., Tsetlin, V.I., Utkin, Y.N., Inozemtseva, L.S., Grivennikov, I.A., 2001. Two forms of nerve growth factor from cobra venom prevent the death of PC12 cells in serum-free medium. J. Nat. Toxins 10, 9-16.

Kulkeaw, K., Chaicumpa, W., Sakolvaree, Y., Tongtawe, P., Tapchaisri, P., 2007. Proteome and immunome of the venom of the Thai cobra, Naja kaouthia. Toxicon 49, 1026-1041.

Kulkeaw, K., Sakolvaree, Y., Srimanote, P., Tongtawe, P., Maneewatch, S., Sookrung, N., Tungtrongchitr, A., Tapchaisri, P., Kurazono, H., Chaicumpa, W., 2009. Human monoclonal ScFv neutralize lethal Thai cobra, Naja kaouthia, neurotoxin. J. Proteomics 72, 270-282. 
Kyi, S.W., Zug, G.R., 2003. Unusual foraging behaviour of Naja kaouthia at the Moyingye Wetlands Bird Sanctuary, Myanmar. Hamadryad 27, 265-266.

Laustsen, A.H., Lomonte, B., Lohse, B., Fernández, J., Gutiérrez, J.M., 2015. Unveiling the the nature of black mamba (Dendroaspis polylepis) venom through venomics and antivenom immunoprofiling: identification of key toxin targets for antivenom development. J. Proteomics (submitted).

Lomonte, B., Tsai, W.C., Ureña-Díaz, J.M., Sanz, L., Mora-Obando, D., Sánchez, E.E., Fry, B.G., Gutiérrez, J.M., Gibbs, H.L., Calvete, J.J., 2014a. Venomics of New World pit vipers: genus-wide comparisons of venom proteomes across Agkistrodon. J. Proteomics 96, 103-116.

Lomonte, B., Pla, D., Sasa, M., Tsai, W.C., Solórzano, A., Ureña-Díaz, J.M., FernándezMontes, M.L., Mora-Obando, D., Sanz, L., Gutiérrez, J.M., Calvete, J.J., 2014b. Two color morphs of the pelagic yellow-bellied sea snake, Pelamis platura, from different locations of Costa Rica: snake venomics, toxicity, and neutralization by antivenom. J. Proteomics 103, 137-152.

Masathien, C., Billings, P., Ratananbanangkoon, K., 1994. Production and characterization of monoclonal antibodies neutralizing the postsynaptic neurotoxin 3 from Naja kaouthia venom. J. Nat. Toxins 3, 155-163.

Meng, Q.X., Wang, W.Y/, Lu, Q.M/, Jin, Y., Wei, J.F., Zhu, S.W., Xiong, Y.L., 2002. A novel short neurotoxin, cobrotoxin c, from monocellate cobra (Naja kaouthia) venom: isolation and purification, primary and secondary structure determination, and tertiary structure modeling. Comp. Biochem. Physiol. 132C, 113-121. 
Mukherjee, A.K., Maity, C.R., 2001. Biochemical composition, lethality and pathophysiology of venom from two cobras - Naja naja and N. kaouthia. Comp. Biochem. Physiol. B 131, 125-132.

Pakmanee, N., Khow, O., Kumsap, W., Omori-Satoh, T., Chanhome, L., Sriprapat, S., Sitprija, V., 1998. Envenomation of mice by Thai cobra (Naja kaouthia) venom: tolerable venom concentration and exposure time. Toxicon $36,809-812$.

Prakash, S., Mishra, A.K., Raziuddin, M., 2012.A new record of cream coloured morph of Naja kaouthia Lesson, 1831 (Reptilia, Serpentes, Elapidae) from Hazaribag, Jharkhand, India. Biodiversity J. 3, 153-155.

Reali, M., Serafim, F.G., da Cruz-Hofling, M.A., Fontana, M.D., 2003. Neurotoxic and myotoxic actions of Naja naja kaouthia venom on skeletal muscle in vitro. Toxicon $41,657-665$.

Richard, G., Meyers, A.J., McLean, M.D., Arbabi-Ghahroudi, M., MacKenzie, R., Hall, J.C., 2013. In vivo neutralization of alpha-cobratoxin with high-affinity llama single-domain antibodies $\left(\mathrm{V}_{\mathrm{H}} \mathrm{Hs}\right)$ and a $\mathrm{V}_{\mathrm{H}} \mathrm{H}-\mathrm{Fc}$ antibody. PLoS One 8, e69495.

Roncolato, E.C., Campos, L.B., Pessenda, G., Costa e Silva, L., Furtado, G.P., Barbosa, J.E., 2015. Phage display as a novel promising antivenom therapy: a review. Toxicon 93, 79-84.

Safdari, Y., Farajnia, S., Asgharzadeh, M., Khalili, M., 2013. Antibody humanization methods - a review and update. Biotech. Gen. Eng. Rev. 29, 175-186.

Sakurai, Y., Takatsuka, H., Yoshioka, A., Matsui, T., Suzuki, M., Titani, K., Fujimura, Y., 2001. Inhibition of human platelet aggregation by L-amino acid oxidase purified from Naja naja kaouthia venom. Toxicon 39, 827-1833. 
Stewart, C.S., MacKenzie, C.R., Hall, J.C., 2007. Isolation, characterization and pentamerization of alpha-cobrotoxin specific single-domain antibodies from a naive phage display library: preliminary findings for antivenom development. Toxicon 49 , 699-709.

Stuart, B., Wogan, G., 2012. Naja kaouthia. In: The IUCN Red List of Threatened Species. Version 2014.3. http://www.iucnredlist.org. Downloaded on 19 January 19, 2015.

Tan, N.H., Swaminathan, S., 1992. Purification and properties of the L-amino acid oxidase from monocellate cobra Naja naja kaouthia venom. Int. J. Biochem. 24, 967-973.

Uetz, P., Hošek, J., 2015. The Reptile Database, http://www.reptile-database.org. Accessed January 26, 2015.

Utsintong, M., Talley, T.T., Taylor, P.W., Olson, A.J., Vajragupta, O., 2009. Virtual screening against $\alpha$-Cobratoxin. J. Biomol. Screening 14, 1109-1118.

Viravan, C., Veeravat, U., Warrell, M.J., Theakston, R.G.D., Warrell, D.A., 1986. ELISA confirmation of acute and past envenoming by the monocellate Thai cobra (Naja kaouthia). Am. J. Trop. Med. Hyg. 35, 173-181.

Vonk, F.J., Casewell, N.R., Henkel, C.V., Heimberg, A.M., Jansen, H.J., McCleary, R.J.R., Kerkkamp, H.M., Vos, R.A., Guerreiro, I., Calvete, J.J., Wüster, W., Woods, A.E., Logan, J.M., Harrison, R.A., Castoe, T.A., de Koning, A.P., Pollock, D.D., Yandell, M., Calderon, D., Renjifo, C., Currier, R.B., Salgado, D., Pla, D., Sanz, L., Hyder, A.S., Ribeiro, J.M., Arntzen, J.W., van den Thillart, G.E., Boetzer, M., Pirovano, W., Dirks, R.P., Spaink, H.P., Duboule, D., McGlinn, E., Kini, R.M., Richardson, M.K., 2013. The king cobra genome reveals dynamic gene evolution and adaptation in the snake venom system. Proc. Natl. Acad. Sci. USA 110, 20651-20656. 
659 Wallach, V., Wüster, W., Broadley, D.G., 2009. In praise of subgenera: taxonomic status of 660 cobras of the genus Naja Laurenti (Serpentes: Elapidae). Zootaxa 2236, 26-36.

661 Wang, J.P., Teng, C.M., 1990. Comparison of the enzymatic and edema-producing 662 activities of two venom phospholipase $A_{2}$ enzymes. Eur. J. Pharmacol. 190, 347354.

Wang, W.J., Shih, C.H., Huang, T.F., 2004. A novel P-I class metalloproteinase with broad substrate-cleaving activity, agkislysin, from Agkistrodon acutus venom. Biochem. Biophys. Res. Comm. 324, 224-230.

Warrell, D.A., 1995. Clinical toxicology of snakebite in Africa and the Middle East / Arabian peninsula. In: Handbook of Clinical Toxicology of Animal Venoms and Poisons (Meier, J., White, J., Eds.), pp 433-492. CRC Press.

Warrell, D.A., 2010. Snake bite. Lancet 375, 77-88.

Warrell, D.A., 2010b. Guidelines for the management of snake-bites. World Health Organization, $152 \mathrm{pp}$.

Wongtongkam, N., Wilde, H., Sitthi-Amorn, C., Ratanabanangkoon, K., 2005. A study of Thai cobra (Naja kaouthia) bites in Thailand. Mil. Med. 170, 336-341.

Wüster, W., 1996. Taxonomic changes and toxinology: Systematic revisions of the asiatic cobras (Naja naja species complex). Toxicon 34, 399-406. 
$678 \quad$ Figure legends

679

680 Figure 1: Separation of N. kaouthia (A) venom proteins by RP-HPLC (C), followed by

SDS-PAGE (B). Two mg of venom were fractionated on a $\mathrm{C}_{18}$ column and eluted with an acetonitrile gradient (dashed line), as described in Methods. Fractions were further separated by SDS-PAGE under reducing conditions. Molecular weight markers (Mw) are indicated in $\mathrm{kDa}$. Coomassie-stained bands were excised, in-gel digested with trypsin, and subjected to MALDI-TOF/TOF analysis for assignment to protein families, as shown in Table 1.

Figure 2: Composition of $N$. kaouthia venom according to protein families, expressed as percentages of the total protein content. 3FTx: three-finger toxin; PLA 2 : phospholipase $\mathrm{A}_{2}$; NGF: nerve growth factor; OHA: Ohanin/vespryn; CRISP: Cysteine-rich secretory protein; CTL: C-type lectin/lectin-like; NUCL: nucleotidase; PDE: phosphodiesterase; MP: metalloproteinase; LAO: L-amino oxidase; CVF: Cobra venom factor; CTT: Cytidyltransferase; UNK: Unidentified proteins; NP: non-protein components. A division between cytotoxins (CYT) and neurotoxins (NTX) is given for the three-finger toxins.

Figure 3: Presence of selected nucleosides and FAD in Naja kaouthia venom shown by spiking crude venom with $10 \mu \mathrm{g}$ of nucleosides (adenosine, inosine, guanosine) or FAD and separating the venom components by reverse-phase HPLC. If a the peak of a nucleoside coincides with the peak of a venom component, and if mass determination yielded the same mass for the venom component as calculated for the nucleoside, the venom component was 
701 judged to consist of the corresponding nucleoside. $N$. kaouthia venom contains small

702 amounts of adenosine, guanosine, and traces of inosine, but no FAD.

Figure 4: (A) Comparison of the phospholipase $\mathrm{A}_{2}$ activity between the venoms of Naja kaouthia and Micrurus nigrocinctus. N. kaouthia displays some enzymatic activity, although significantly less than M. nigrocinctus. (B) Comparison of the proteolytic activity between the venoms of $N$. kaouthia, M. nigrocinctus, and Bothrops asper, evaluated on azocasein. $N$. kaouthia shows negligible proteinase activity.

Figure 5: Electrospray ionization-mass spectrometry analysis of $N$. kaouthia venom fractions 6 and 10 (see Fig.1 and Table 1). Samples were analyzed in enhanced multicharge positive mode as described in Methods. Fraction $6(\mathrm{Nk}-6)$ presented a homogeneous multi-charged series (A) which deconvoluted to an isotope-averaged mass $\left(\mathrm{M}_{\mathrm{av}}\right)$ of 7826.0

$714 \pm 0.8 \mathrm{Da}(\mathbf{B})$. The multi-charged series of fraction $10(\mathrm{Nk}-10)(\mathbf{C})$ showed a main protein with $\mathrm{M}_{\mathrm{av}} 7619.0 \pm 1.3 \mathrm{Da}$ and a less abundant protein of $7656.0 \pm 0.7 \mathrm{Da}(\mathbf{D})$, thus demonstrating difference between fractions 6 and 10 .

Figure 6: ELISA-based immunoprofiling of human antibodies (Donor 1 IgG: protein Apurified IgG antibodies from Donor 1, Donor 2: protein A-purified IgG antibodies from Donor 2, Human negative: normal human serum from healthy volunteer, never bitten by a snake) to the fractions of Naja kaouthia venom separated by RP-HPLC (see Materials and Methods for details). Toxins with the highest Toxicity Score $(4,5$, and 6$)$ are marked with a skull symbol. 


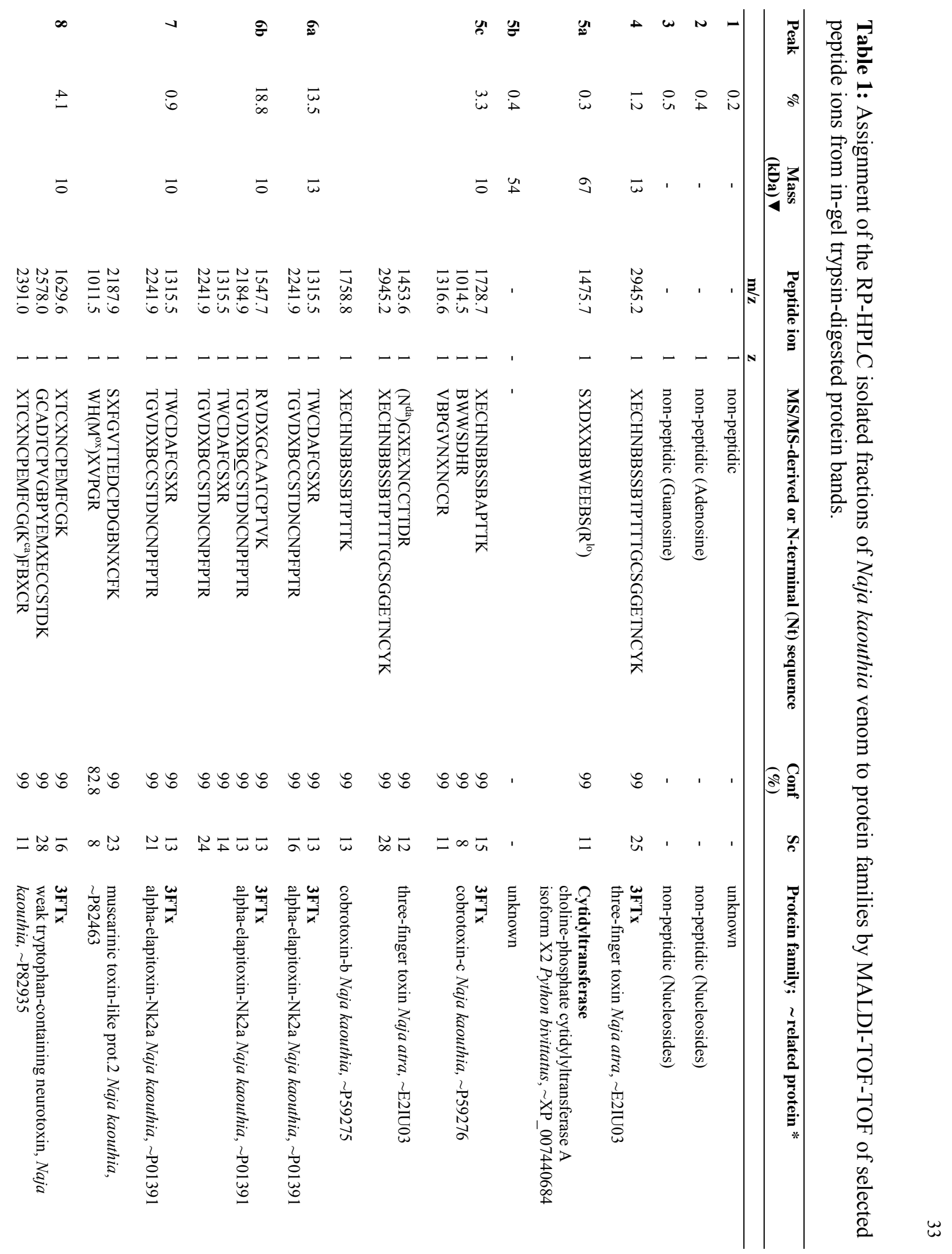




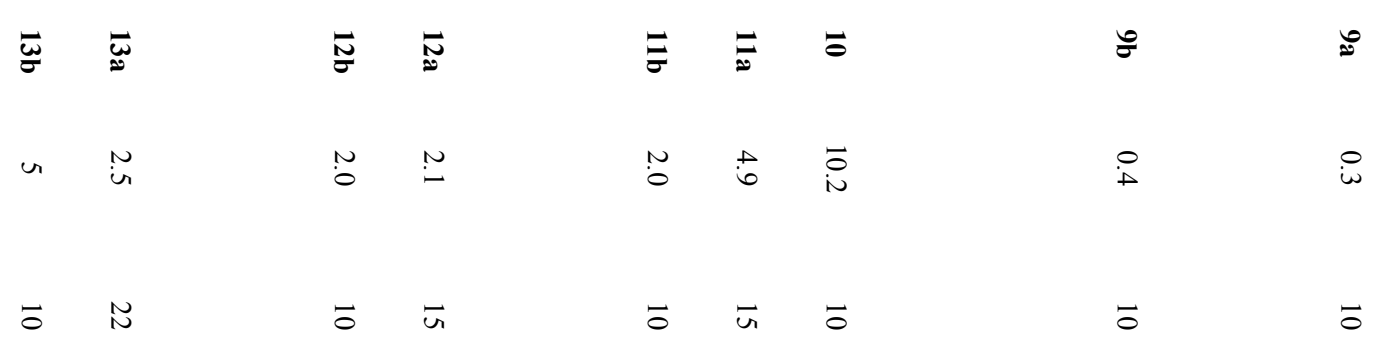

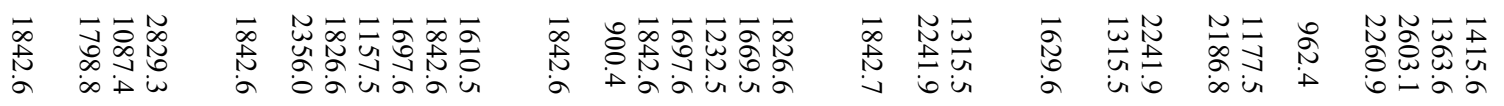

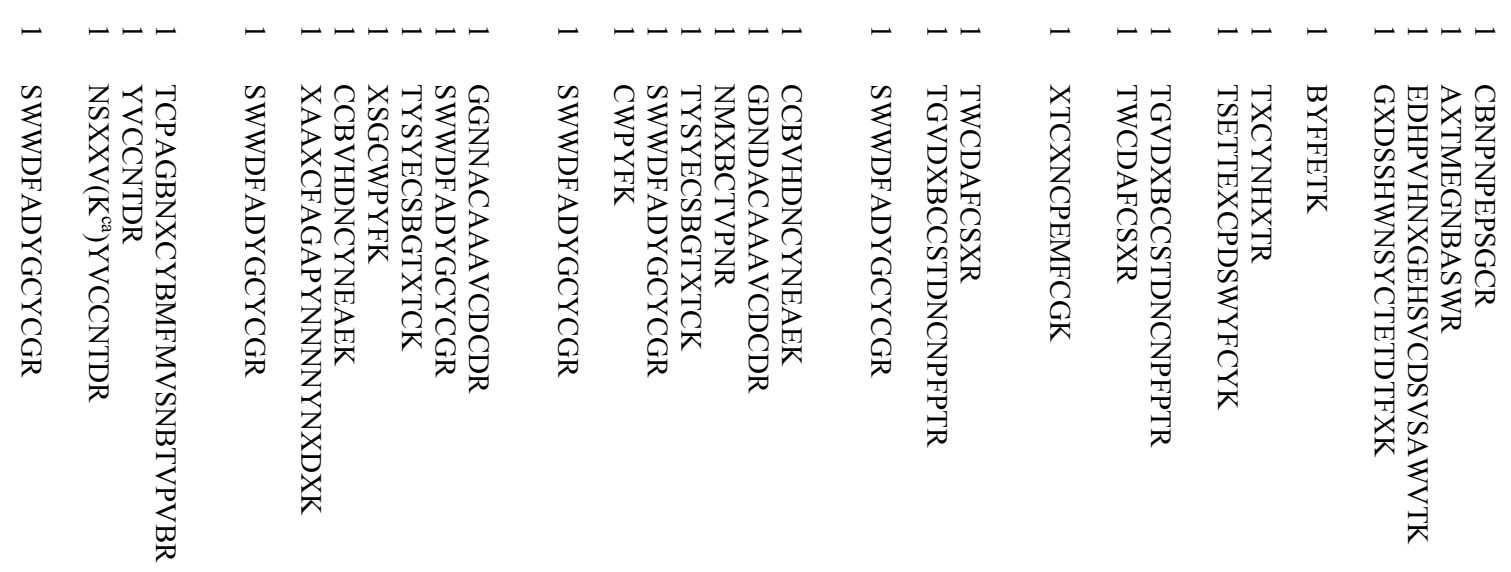

: I பே๐

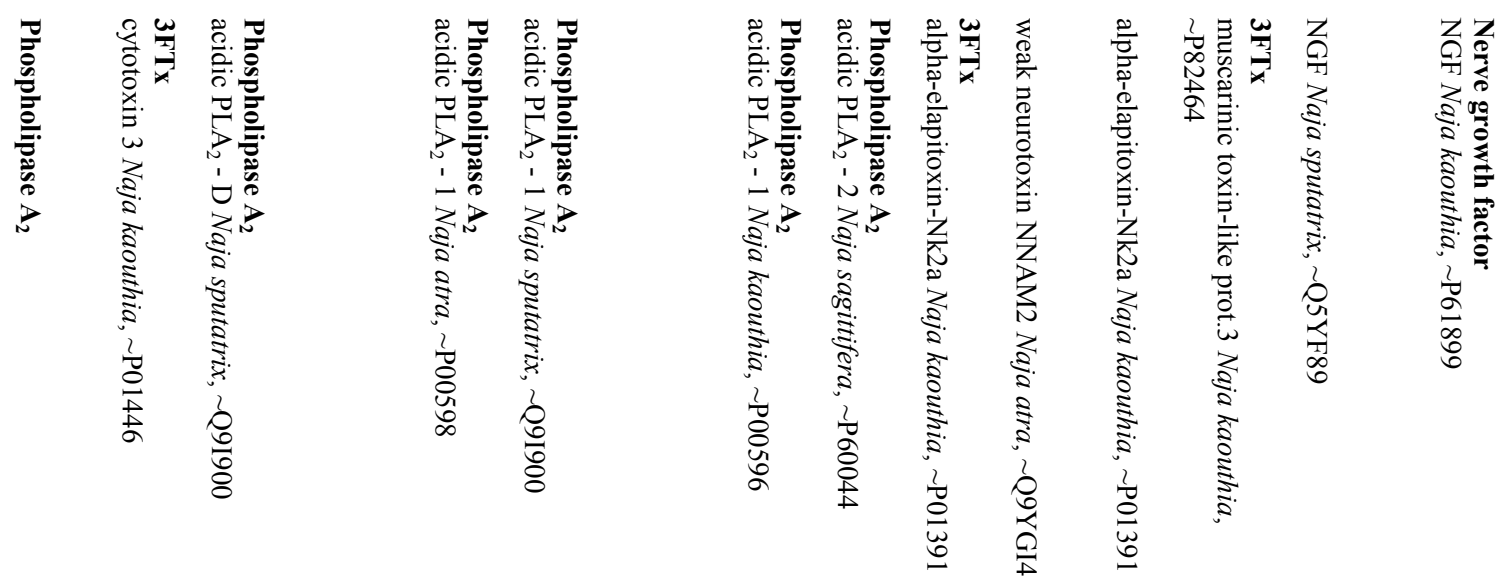




\begin{tabular}{|c|c|c|c|c|c|c|c|c|}
\hline 6 & $\underline{\mathbf{\infty}}$ & $\underset{\mathbb{\infty}}{\mathbb{\infty}}$ & $\vec{\exists}$ & $\vec{\Xi}$ & $\vec{\sigma}$ & $\vec{\otimes}$ & un & $E$ \\
\hline i i & $\stackrel{t}{b}$ & 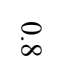 & $\bar{i}$ & in & $\stackrel{\omega}{\dot{w}}$ & $\ddot{b}$ & $\stackrel{n}{\tilde{n}}$ & $\Xi$ \\
\hline $\overrightarrow{0}$ & $\overrightarrow{0}$ & $\bar{\omega}$ & $\bar{\sigma}$ & $\bar{N}$ & o & $\underline{N}$ & $=$ & $\sigma$ \\
\hline
\end{tabular}

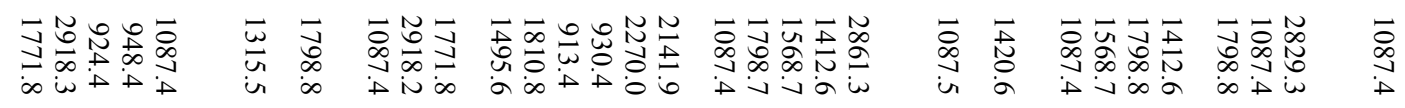

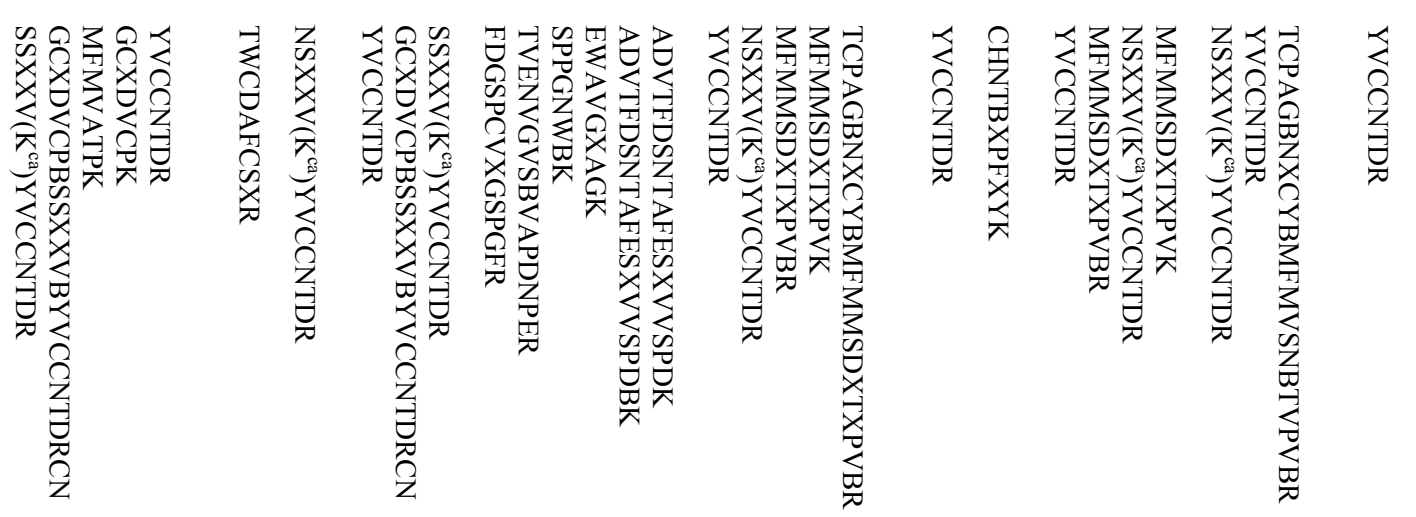

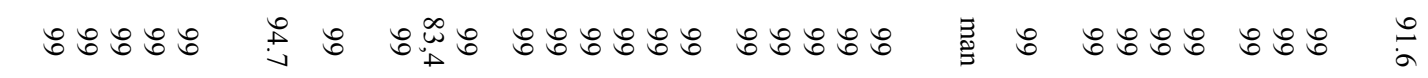
' Ғニるっる

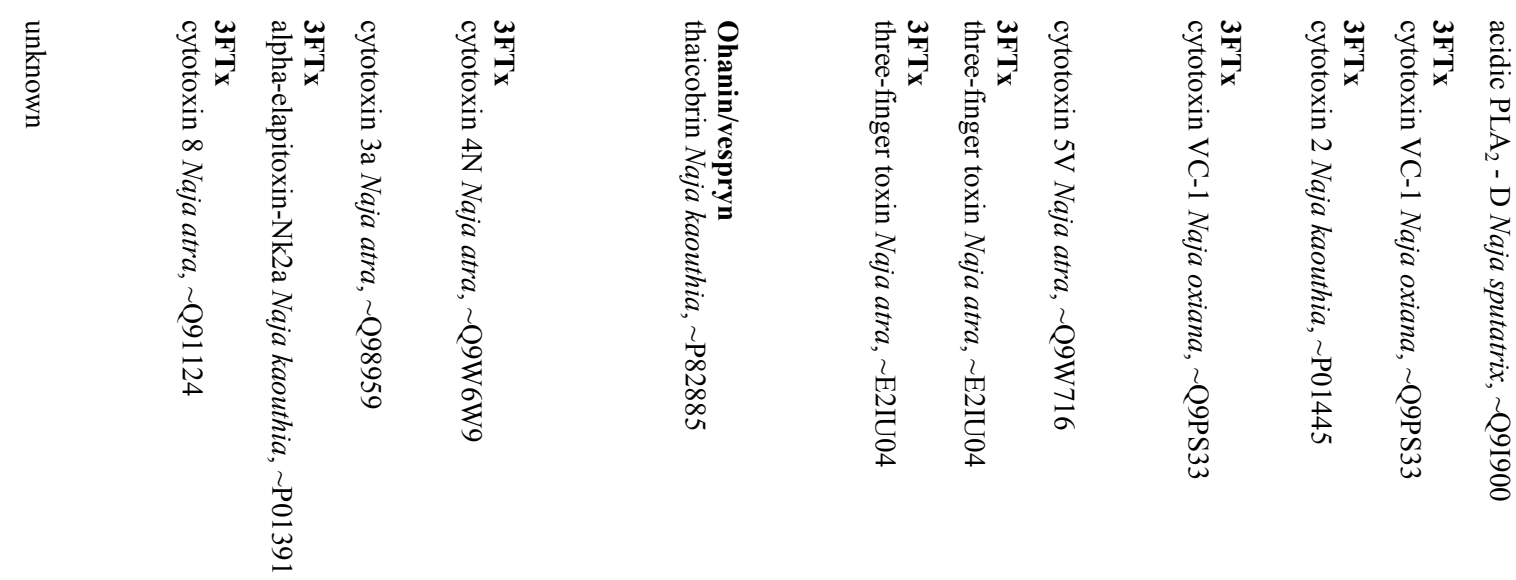




\begin{tabular}{|c|c|c|c|c|c|c|c|c|c|}
\hline$=\frac{\tilde{s}}{\tilde{z}}$ & $\tilde{g}$ & $\stackrel{\mathscr{Y}}{\Psi}$ & $\cong$ & $\widetilde{N}$ & $\tilde{z}$ & $\cong$ & & & \\
\hline : & is & $\stackrel{\circ}{=}$ & $\stackrel{8}{=}$ & 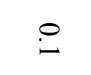 & 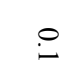 & & & $\stackrel{8}{\circ}$ & 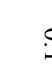 \\
\hline 范 & $\tilde{\alpha}$ & us & $\bar{\sigma}$ & $\bar{N}$ & $\bar{n}$ & & & $\bar{\sigma}$ & \\
\hline
\end{tabular}

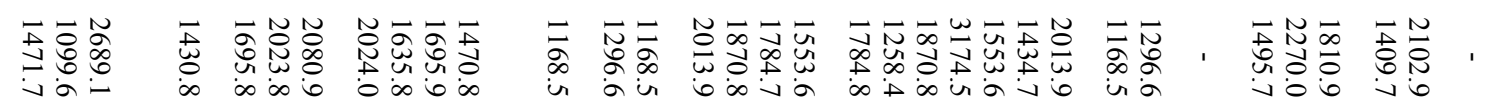

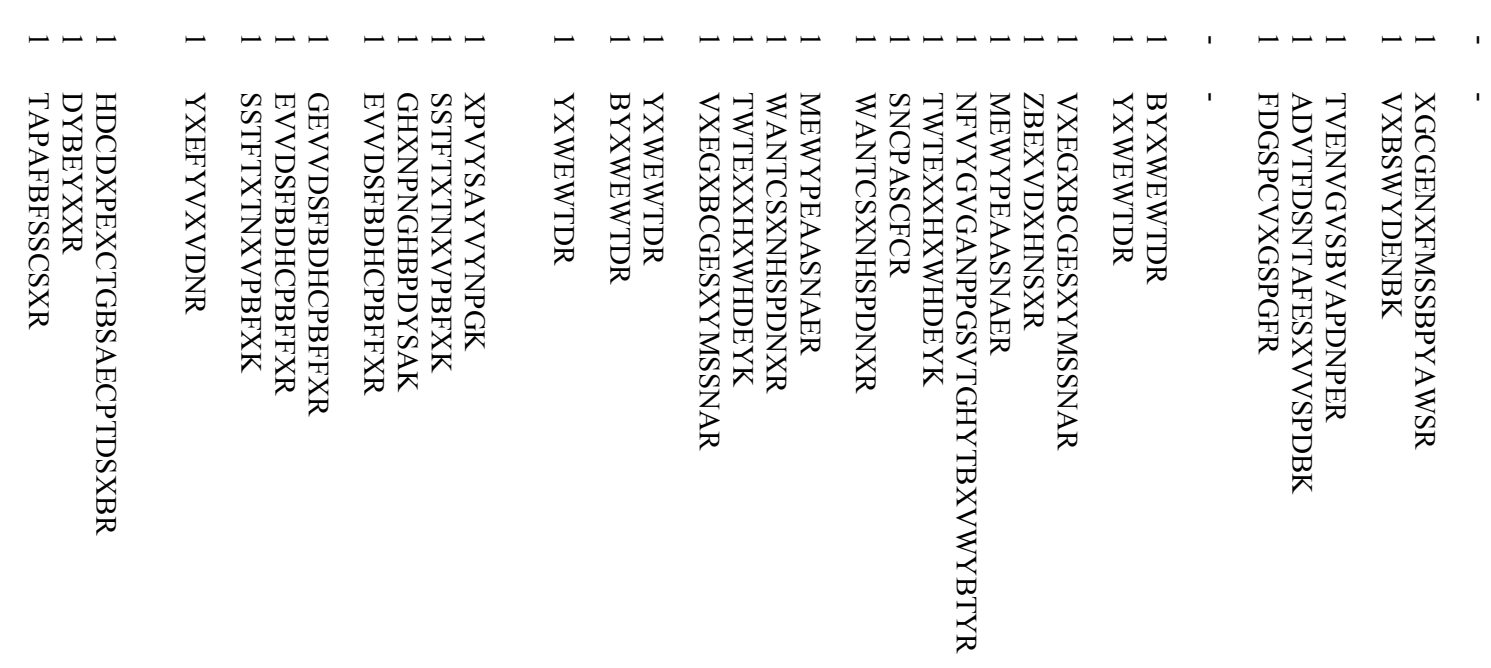

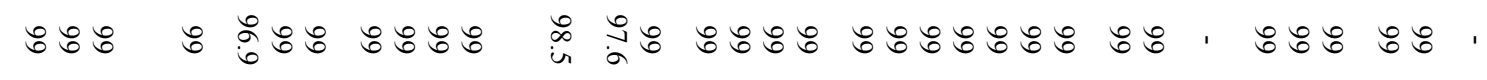

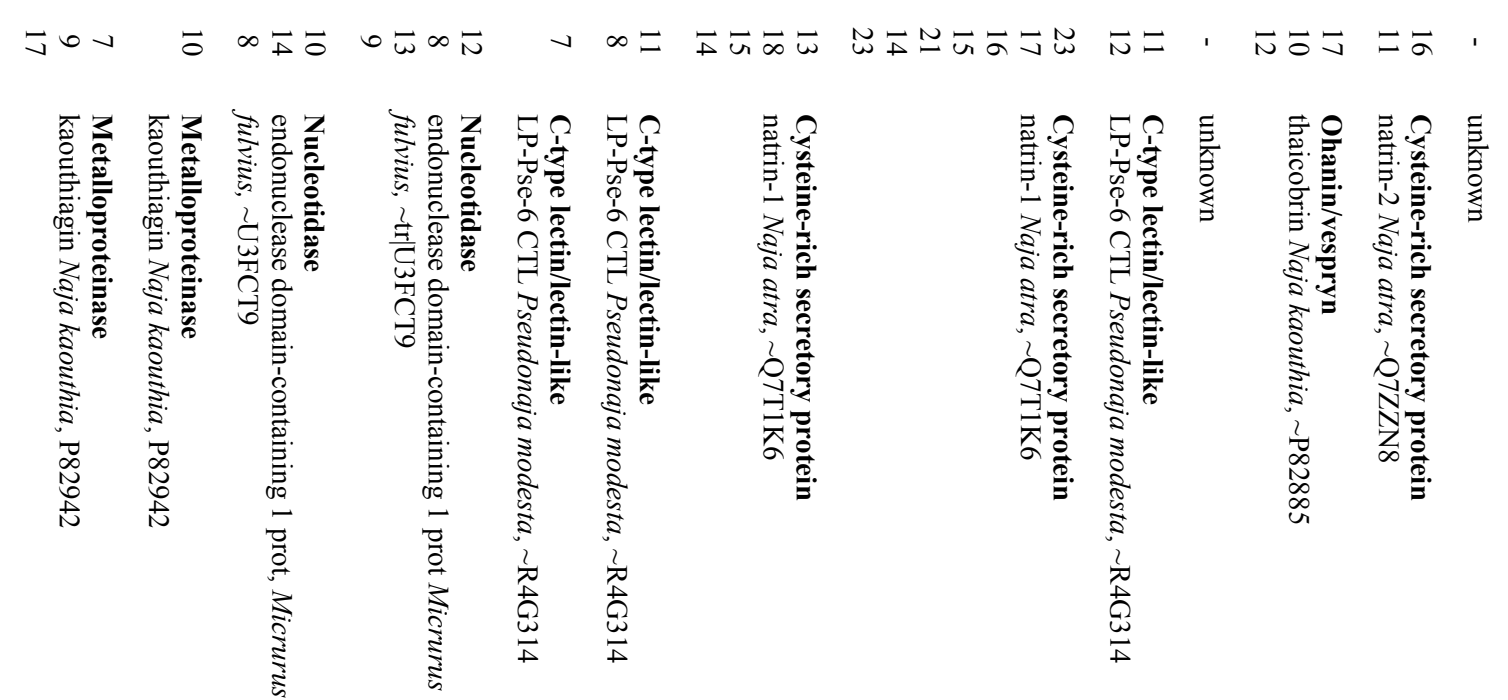




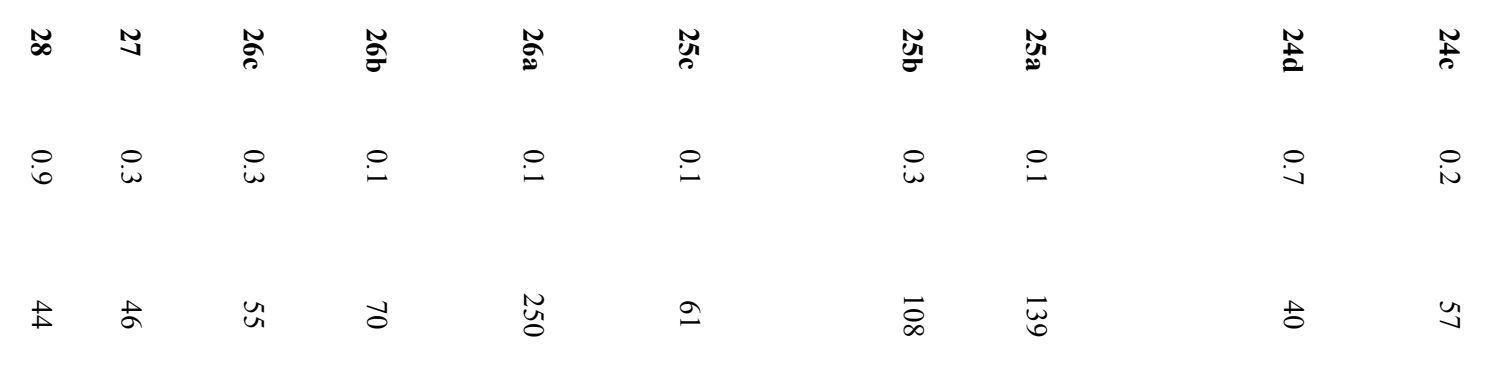

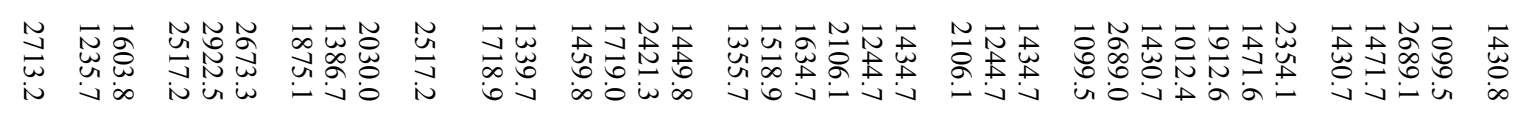

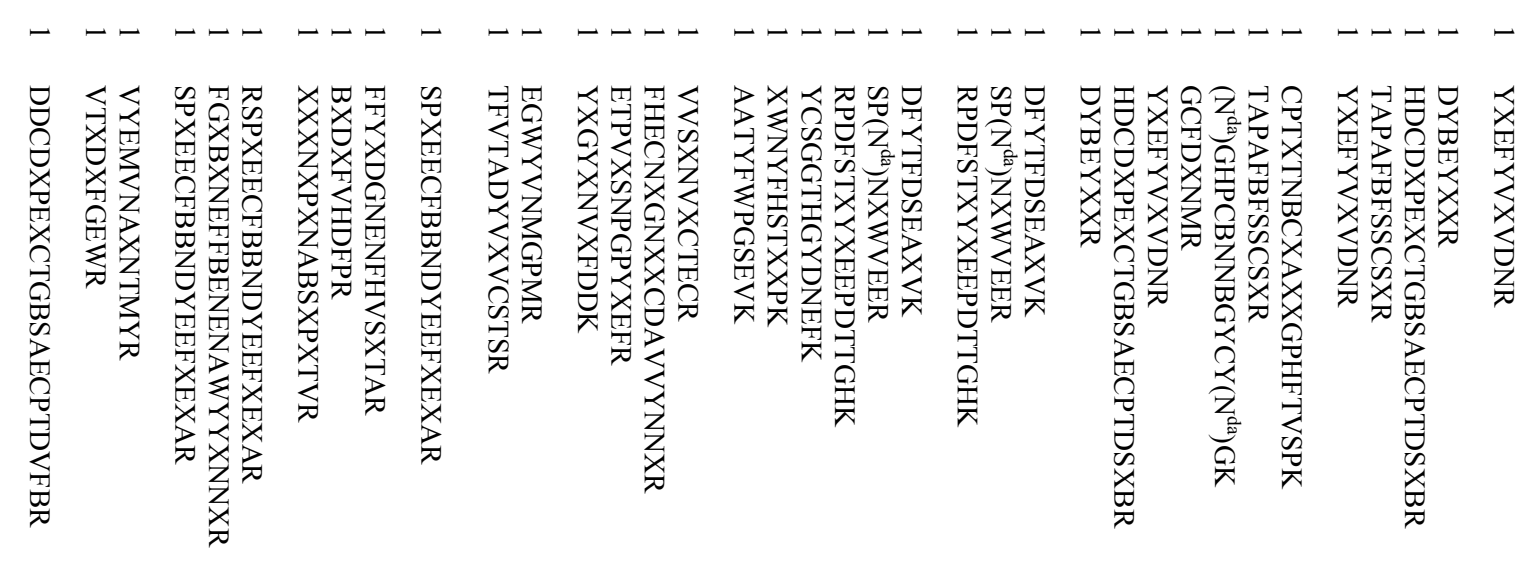

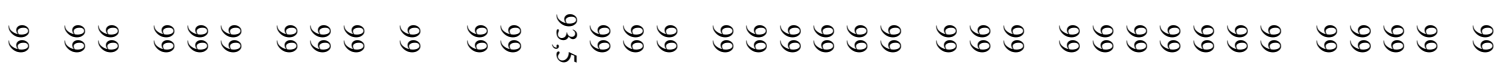
=

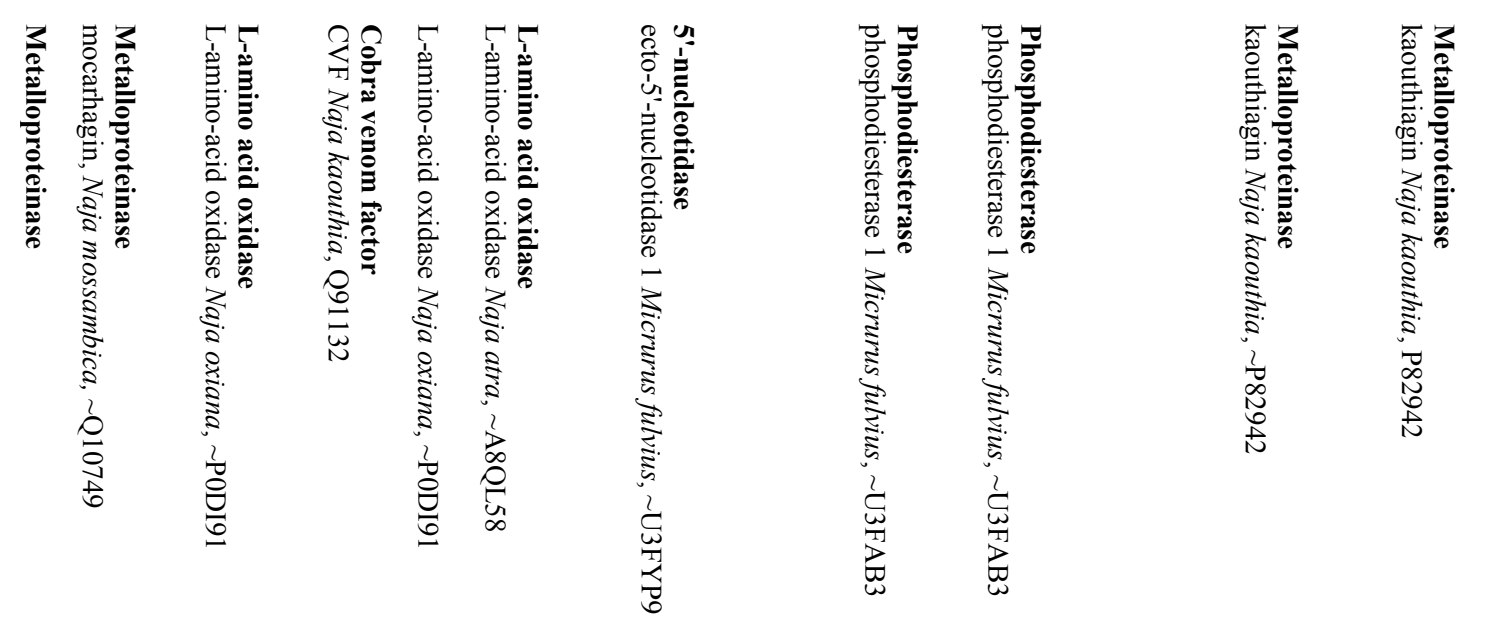




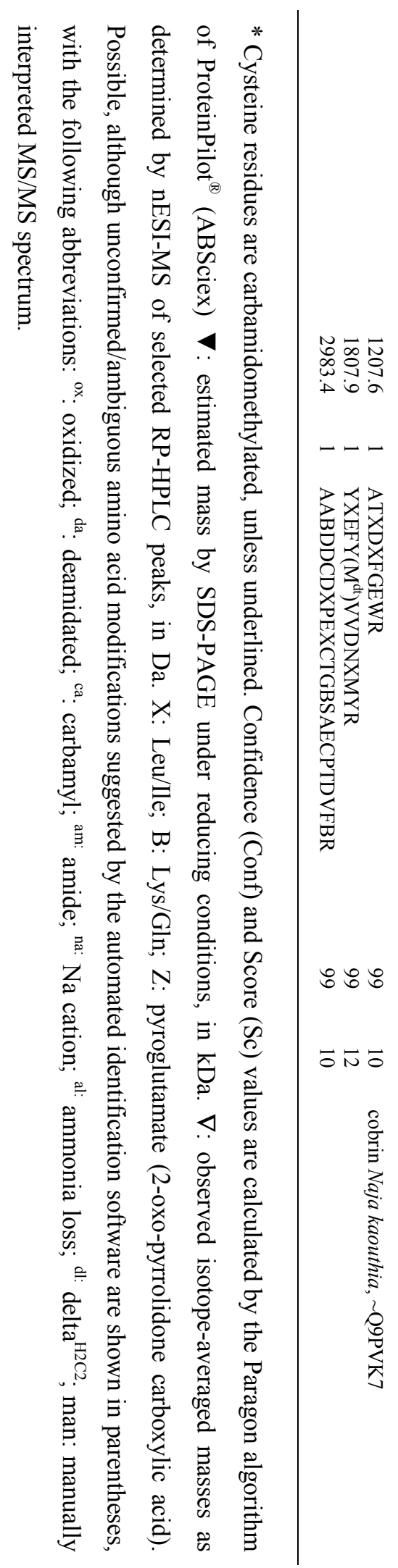

$\underset{\infty}{\omega}$ 


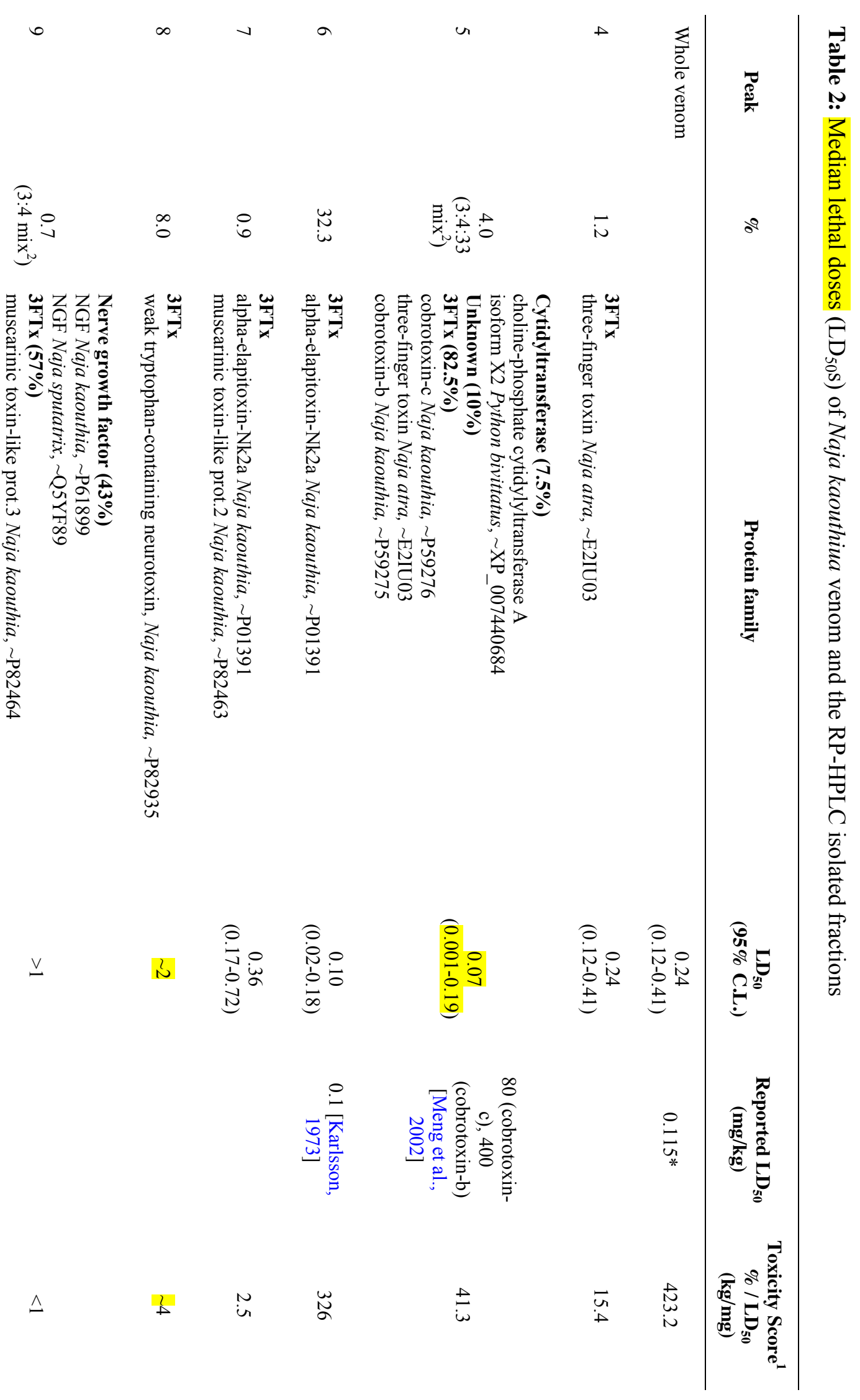




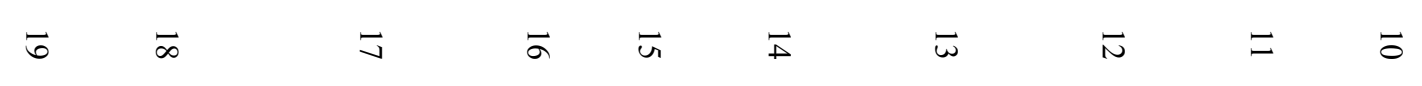

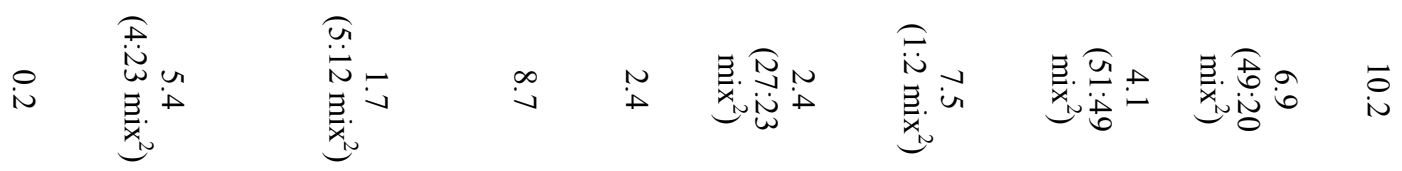

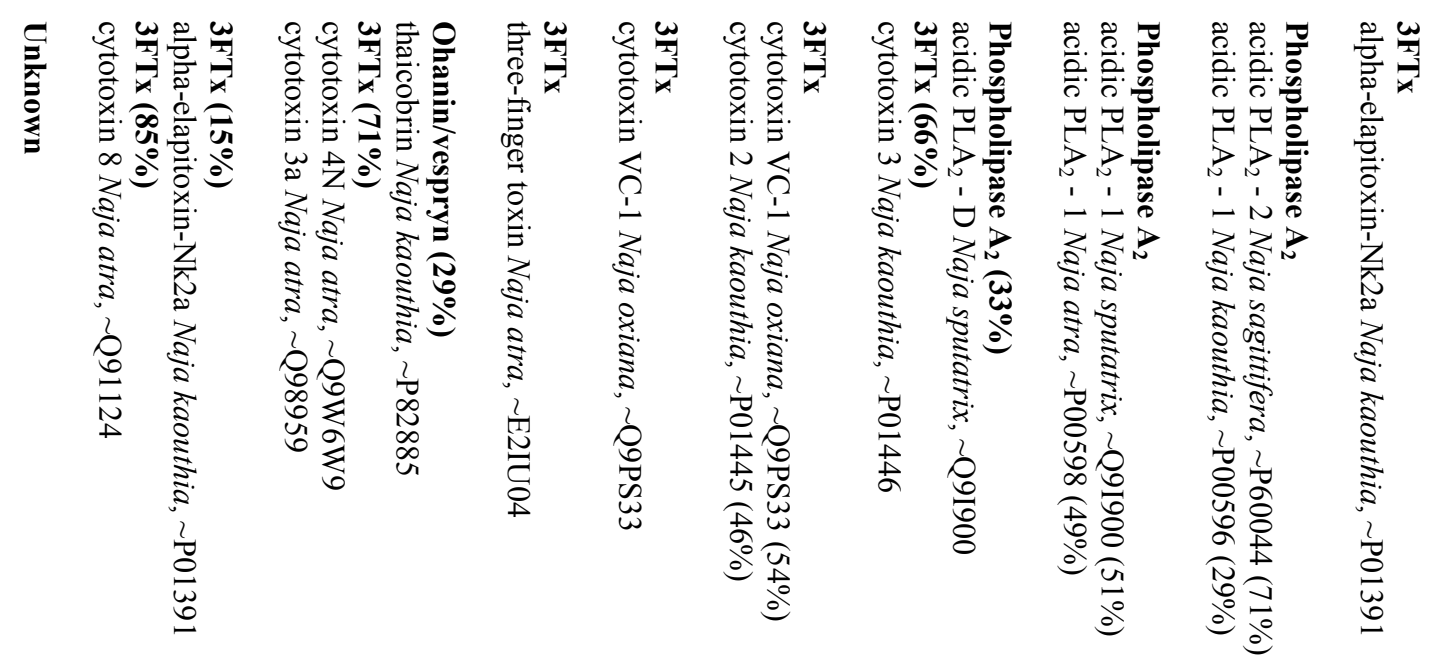

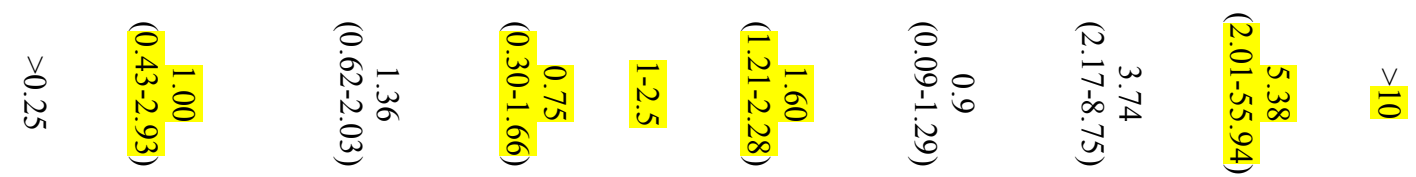

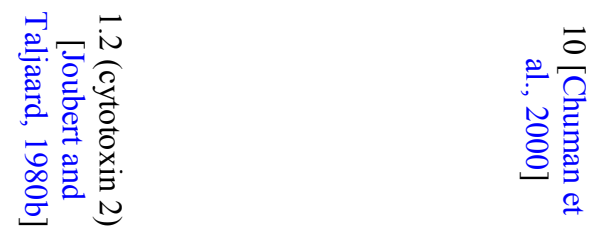

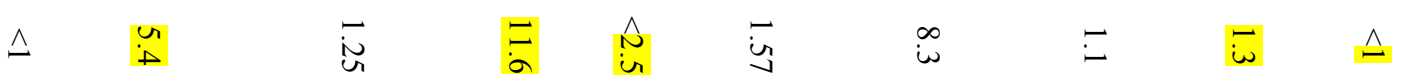




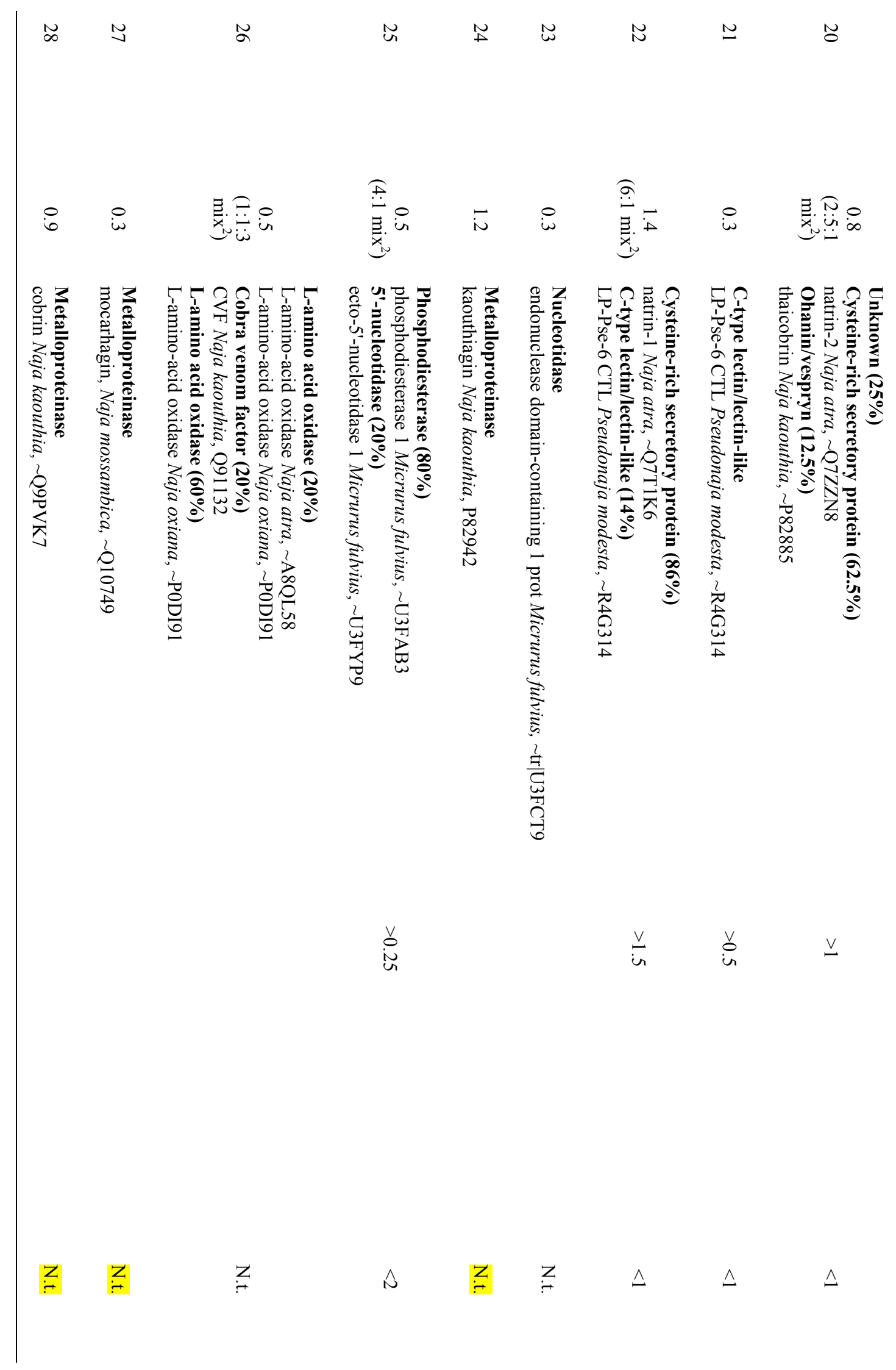




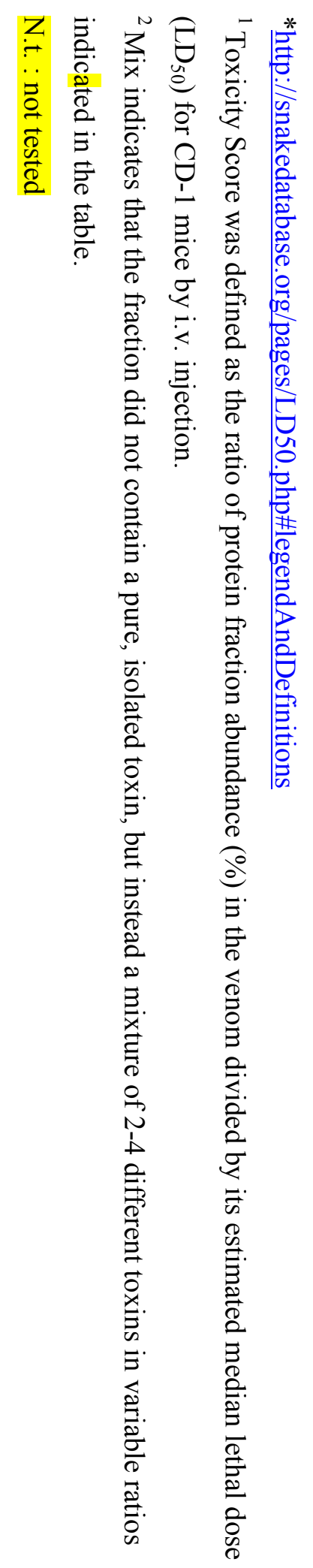




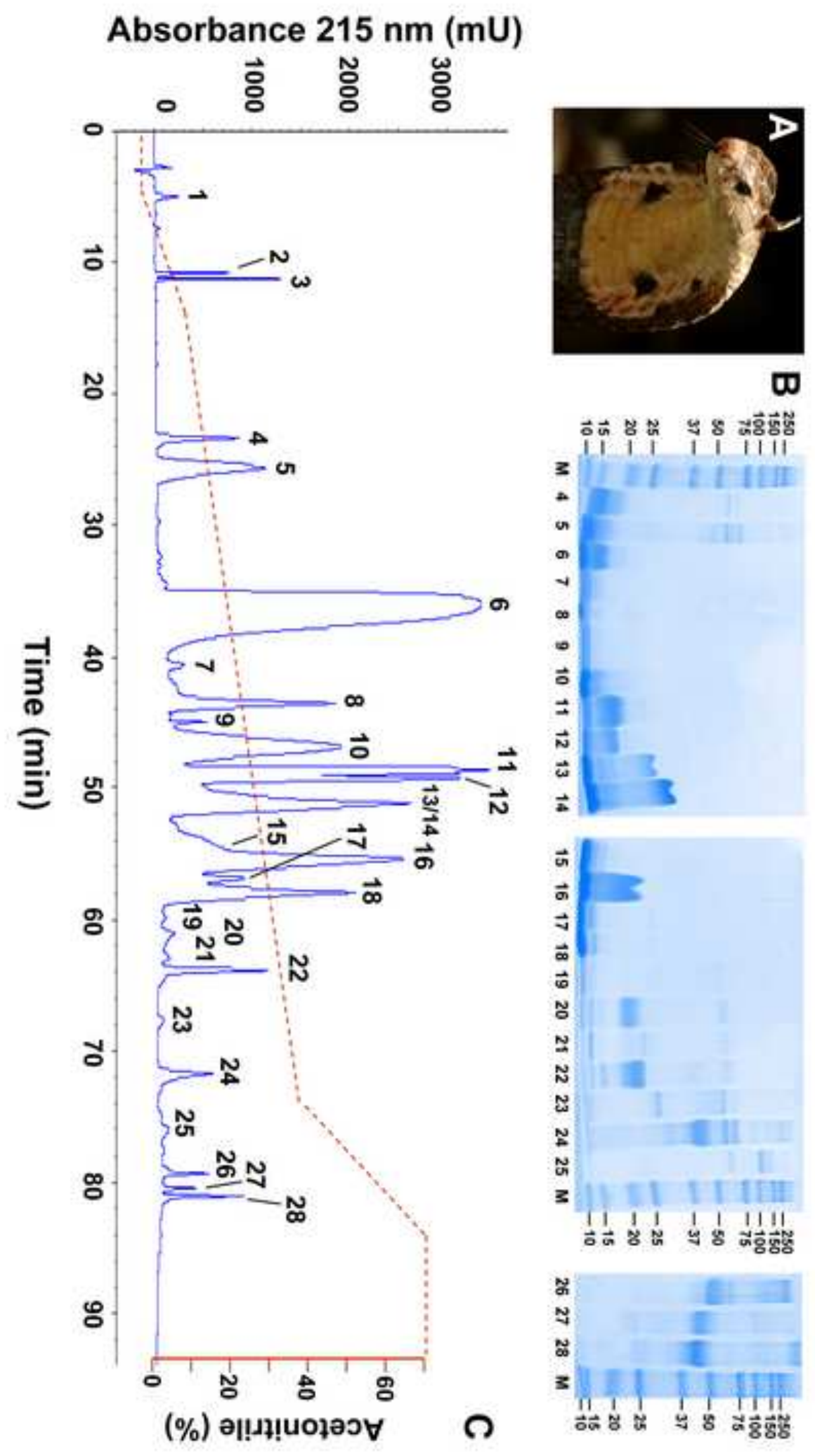

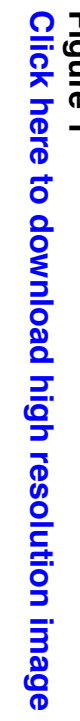


Figure 2

Click here to download high resolution image

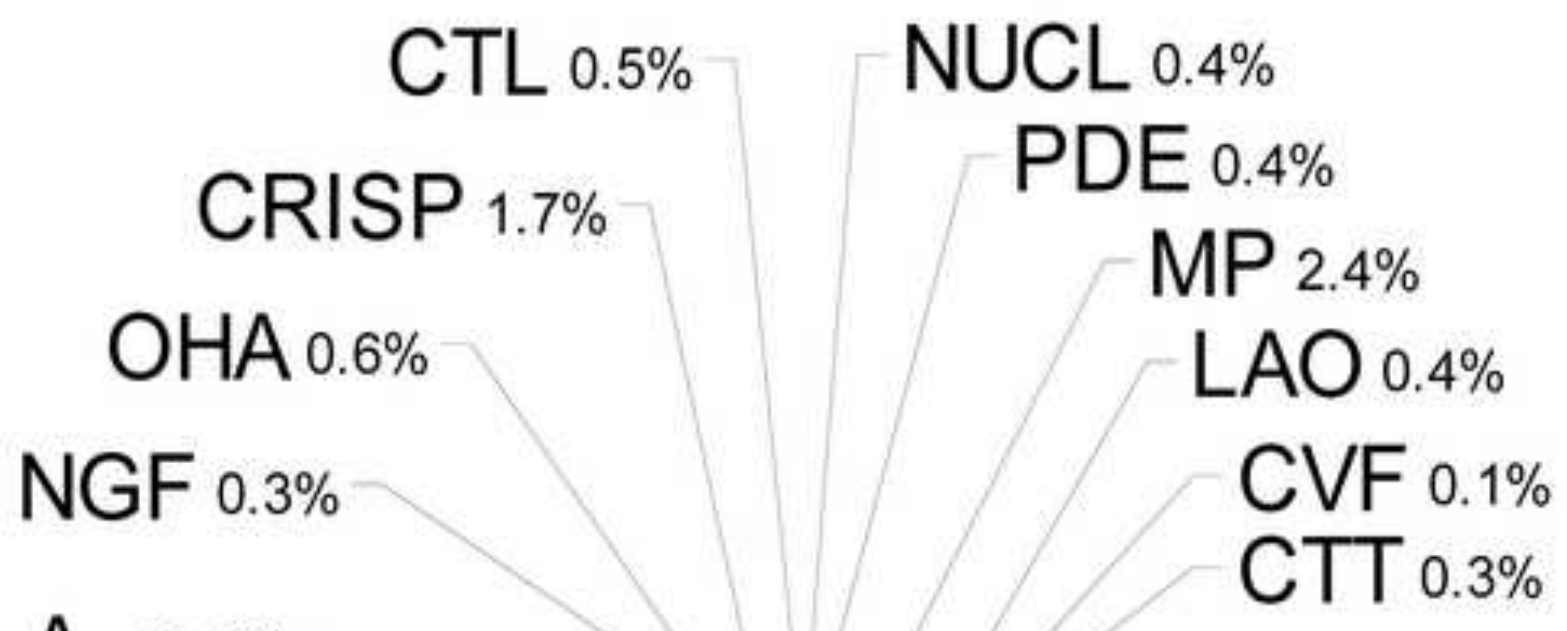

$\mathrm{PLA}_{2} 13.5 \%$

$3 \mathrm{FT} \times 77.5 \%$ 


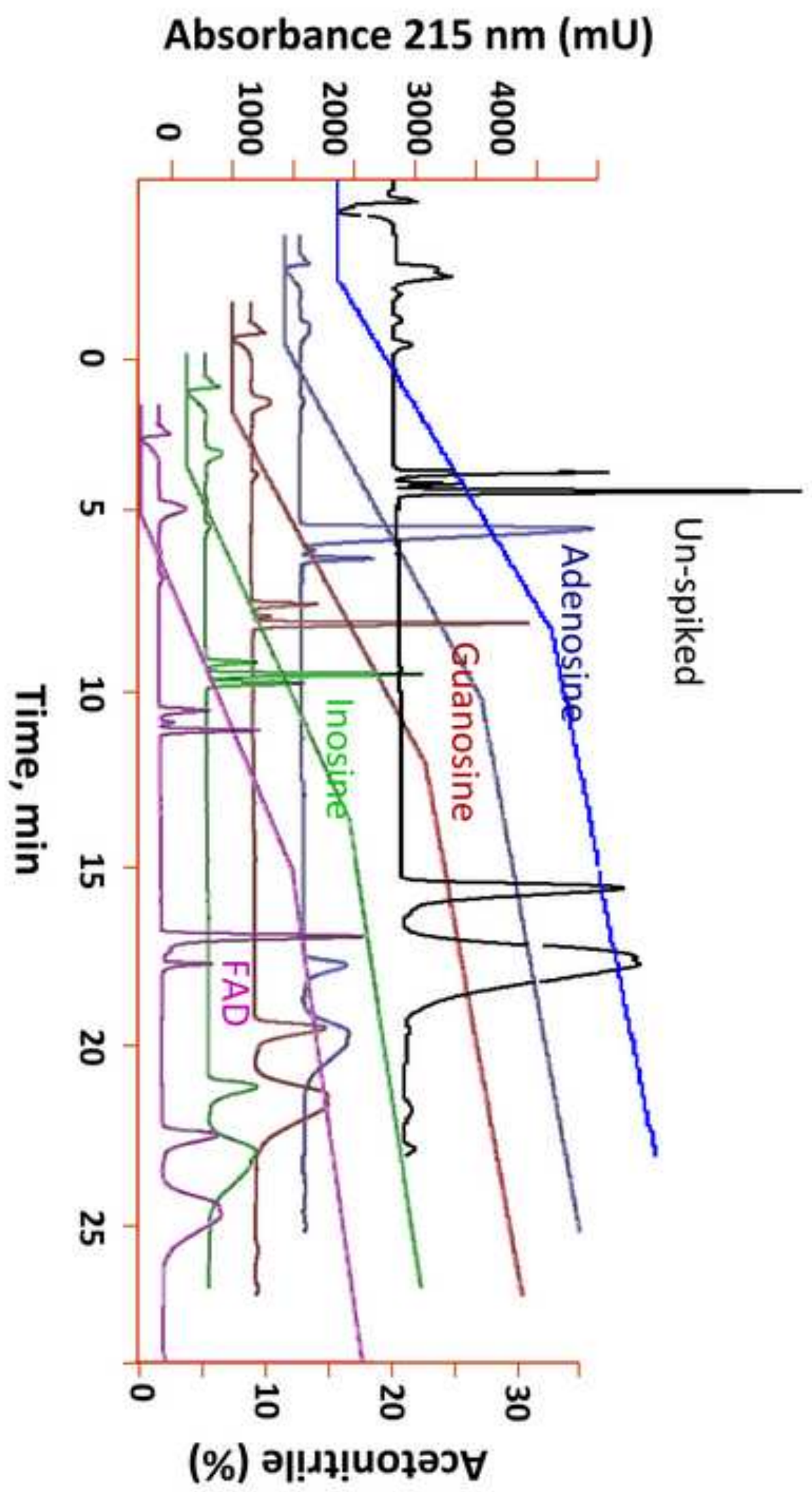

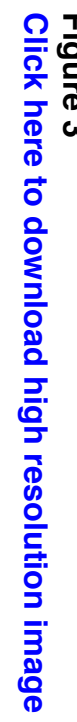



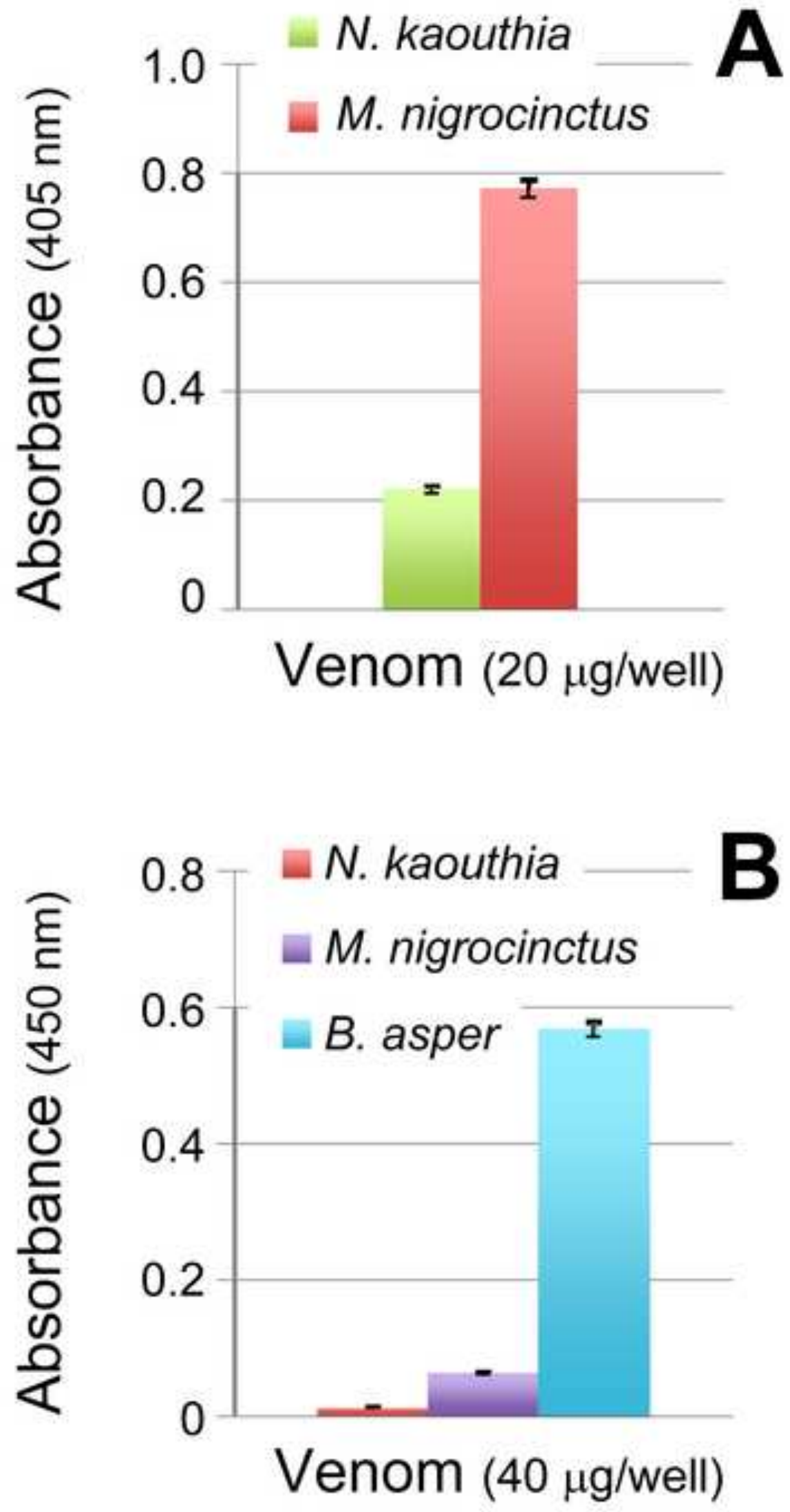


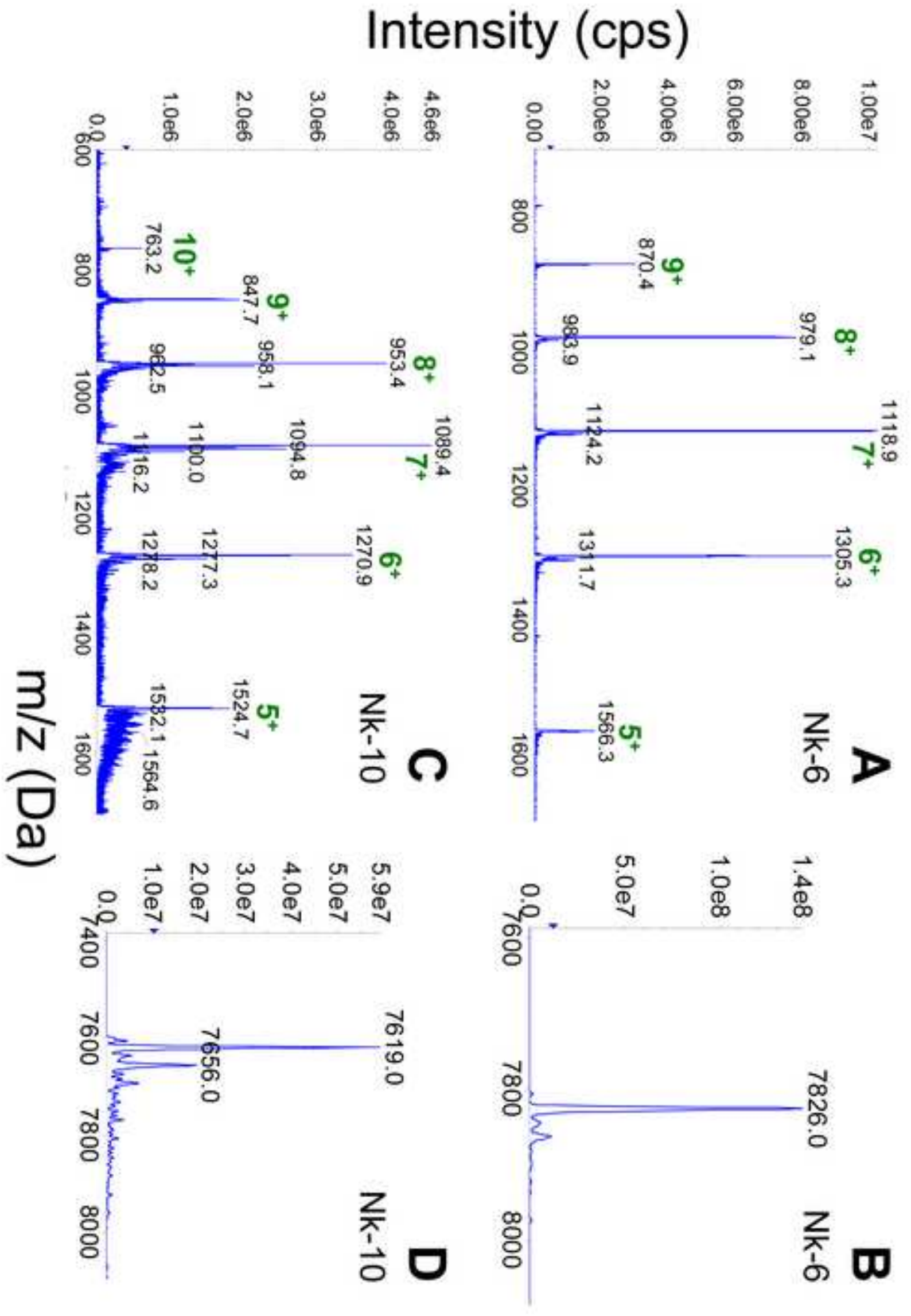




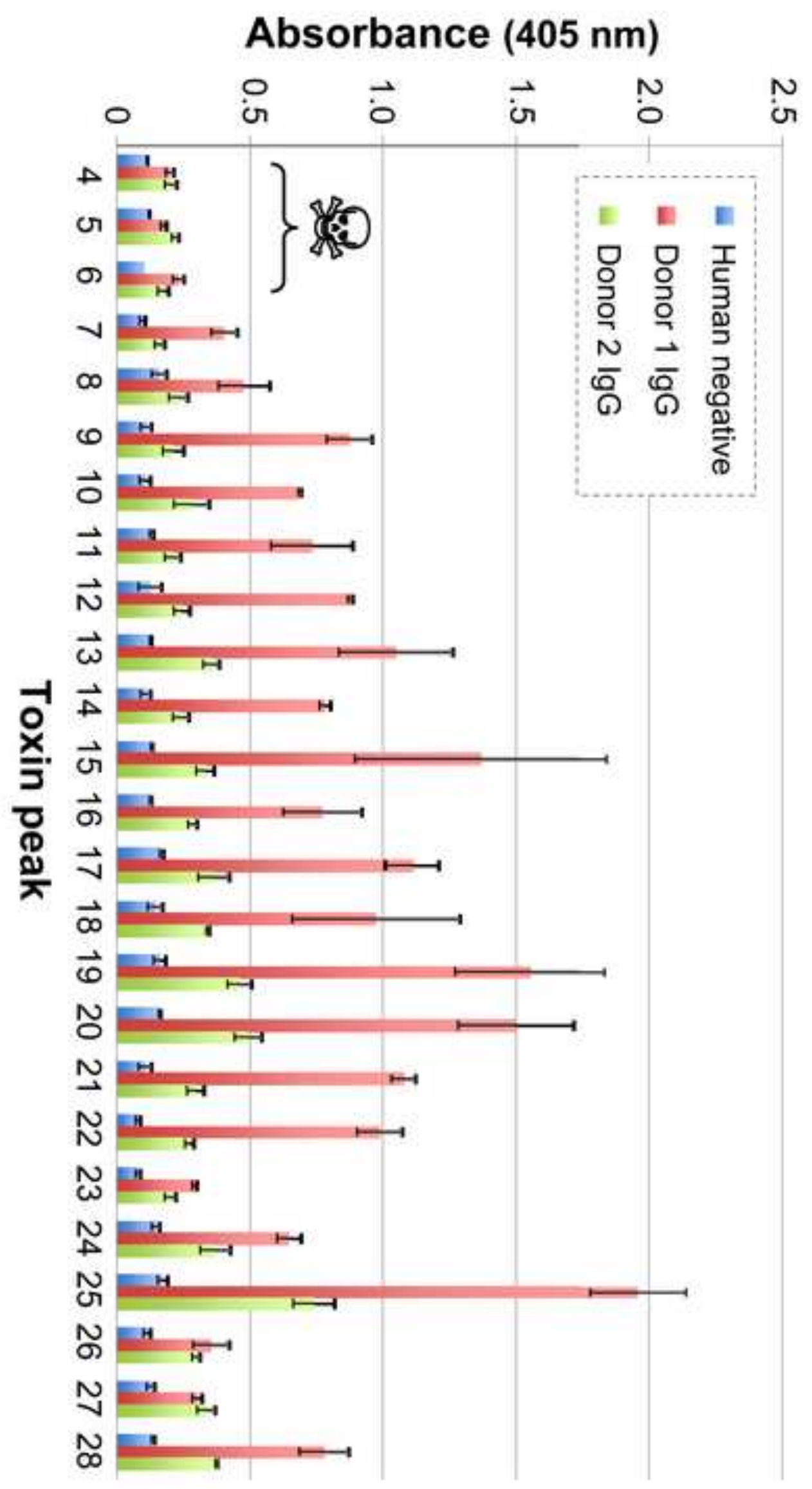

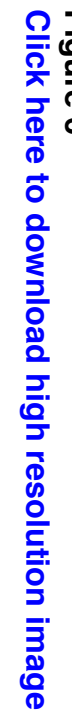




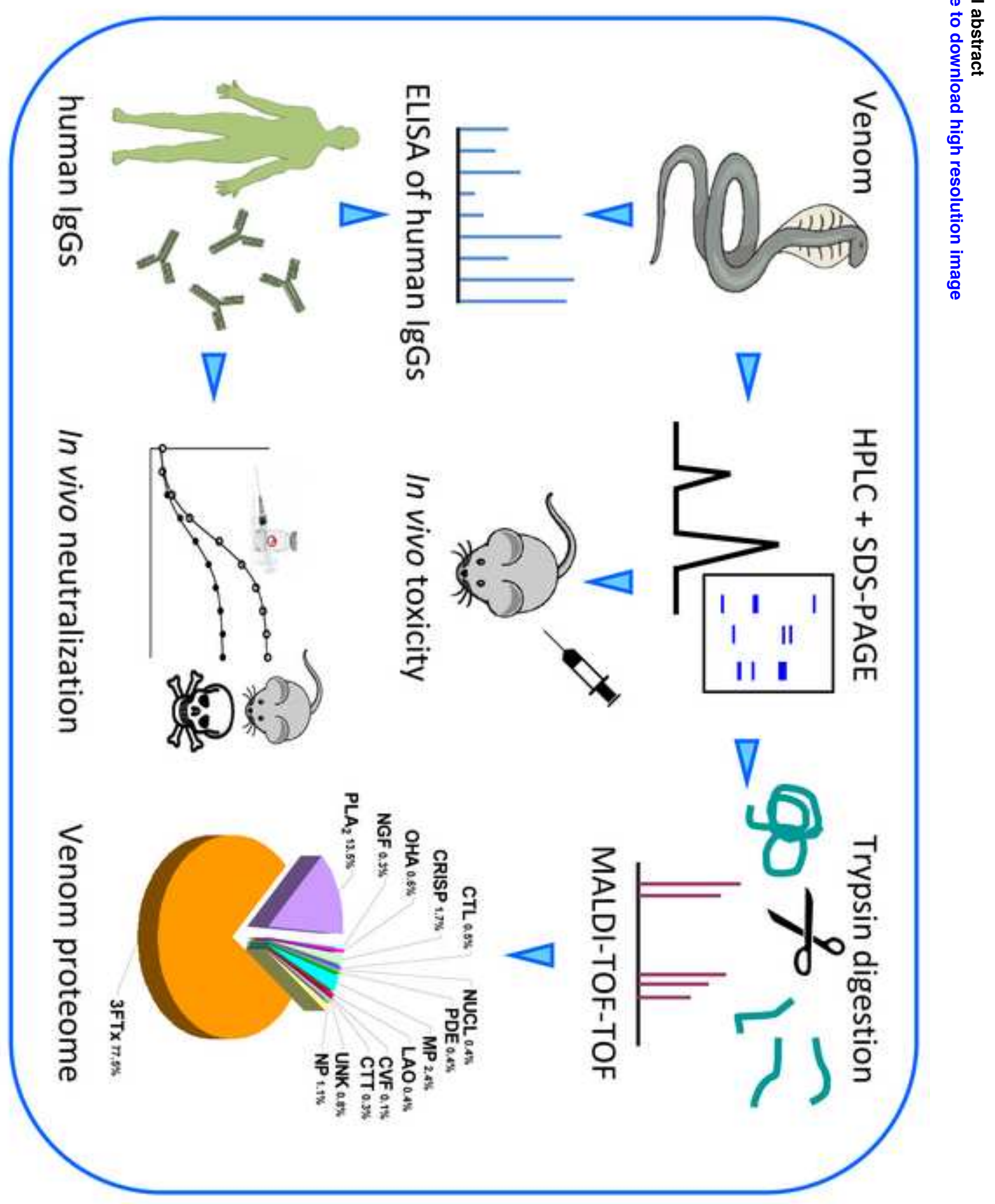

